\title{
Papilionoideae (Leguminosae) do Parque Nacional da Serra da Canastra, Minas Gerais, Brasil
}

\author{
Fabiana Luiza Ranzato Filardi ${ }^{1}$, Flávia Cristina Pinto Garcia ${ }^{1,2}$, Valquíria Ferreira Dutra ${ }^{1}$ e \\ Paula de Souza São-Thiago ${ }^{1}$
}

Recebido: 17.08.2007; aceito: 02.08.2007

ABSTRACT - (Papilionoideae (Leguminosae) of the Serra da Canastra National Park, Minas Gerais, Brazil). The Serra da Canastra National Park is in southwestern Minas Gerais $\left(20^{\circ} 00^{\prime}-20^{\circ} 30^{\prime} \mathrm{S}\right.$ and $\left.46^{\circ} 15^{\prime}-47^{\circ} 00^{\prime} \mathrm{W}\right)$ about $40 \%$ of its area covered by "campos rupestres". Forty-one species of Papilionoideae, grouped into 23 genera and eight tribes, were found. Phaseoleae (Camptosema, Centrosema, Clitoria, Collaea, Eriosema, Erythrina, Galactia, Periandra and Vigna), Dalbergieae (Andira, Dalbergia, Machaerium, Platypodium, Poiretia, Stylosanthes and Zornia), Sophoreae (Acosmium and Bowdichia), Crotalarieae (Crotalaria), Desmodieae (Desmodium), Genisteae (Lupinus), Millettieae (Platycyamus) and Swartzieae (Swartzia). The most numerous genera were Galactia (five species), Andira, Eriosema, Vigna and Zornia, with three species each one. Centrosema, Collaea, Crotalaria, Lupinus, Periandra and Stylosanthes were represented by two species, and the other genera were represented by a single species. The geographical distribution of Eriosema prorepens Benth., Lupinus subsessilis Benth. and Periandra gracilis H.S. Irwin \& Arroyo was extended in this work. Identification keys, descriptions and data on geographical distribution of the species and infra-specific taxa are provided.

Key words: "campos rupestres", "cerrado", flora

RESUMO - (Papilionoideae (Leguminosae) do Parque Nacional da Serra da Canastra, Minas Gerais, Brasil). O Parque Nacional da Serra da Canastra localiza-se no sudoeste de Minas Gerais $\left(20^{\circ} 00^{\prime}-20^{\circ} 30^{\prime} \mathrm{S}\right.$ e $\left.46^{\circ} 15^{\prime}-47^{\circ} 00^{\prime} \mathrm{W}\right)$ e apresenta ca. de $40 \%$ de sua área coberta por campos rupestres. Foram registradas 41 espécies de Papilionoideae reunidas em 23 gêneros e oito tribos: Phaseoleae (Camptosema, Centrosema, Clitoria, Collaea, Eriosema, Erythrina, Galactia, Periandra e Vigna), Dalbergieae (Andira, Dalbergia, Machaerium, Platypodium, Poiretia, Stylosanthes e Zornia), Sophoreae (Acosmium e Bowdichia), Crotalarieae (Crotalaria), Desmodieae (Desmodium), Genisteae (Lupinus), Millettieae (Platycyamus) e Swartzieae (Swartzia). Os gêneros mais representativos em número de espécies foram Galactia (com cinco espécies), Andira, Eriosema, Vigna e Zornia, com três espécies cada um. Os gêneros Centrosema, Collaea, Crotalaria, Lupinus, Periandra e Stylosanthes foram representados por duas espécies, e os demais gêneros por uma espécie cada. A distribuição geográfica de Eriosema prorepens Benth., Lupinus subsessilis Benth. e Periandra gracilis H.S. Irwin \& Arroyo foi ampliada neste trabalho. São apresentadas chaves para identificação, descrições e dados sobre a distribuição geográfica das espécies e táxons infra-específicos.

Palavras-chave: campos rupestres, cerrado, flora

\section{Introdução}

O Parque Nacional da Serra da Canastra (PNSC), segunda maior unidade de conservação de Minas Gerais, apresenta aproximadamente $40 \%$ de sua área coberta por campos rupestres (IBDF 1981), formação vegetacional associada a condições geológicas e climáticas específicas com altos índices de endemismos e espécies raras (Giulietti \& Pirani 1988). Cerca de 4.000 espécies já foram descritas para a flora dos campos rupestres (Giulietti et al. 2000). Os estudos florísticos no PNSC, antes restritos aos realizados pela expedição de Saint Hilaire (Saint Hilaire 1977); ao seu plano de manejo (IBDF 1981); e ao levantamento das espécies arbóreas da mata da Cachoeira da Casca D'Anta, que revelou apenas oito espécies de Papilionoideae (Mota 1984); foram intensificados em 1994 e revelaram a existência de 17 áreas de endemismos, além de dezenas de novas espécies para a ciência (Romero \& Nakajima 1999).

1. Universidade Federal de Viçosa, Departamento de Biologia Vegetal, Av. P.H. Rolfs s.n., 36570-000 Viçosa, MG, Brasil

2. Autora para correspondência: fcgarcia@ufv.br 
A subfamília Papilionoideae reúne mais de 70\% dos representantes de Leguminosae, com 13.800 espécies pertencentes a 467 gêneros e 28 tribos (Lewis et al. 2005). Caracteriza-se por folhas pinadas, nunca bipinadas, flores papilionáceas com simetria zigomorfa e prefloração imbricada vexilar havendo, porém, exceções nas tribos Sophoreae e Swartzieae que apresentam algumas espécies com flores actinomorfas (Polhill \& Raven 1981, Lewis et al. 2005). Na flora dos campos rupestres, Leguminosae está representada por cerca de 338 espécies reunidas em 52 gêneros, sendo Papilionoideae a subfamília mais diversa, com $46 \%$ das espécies e $67 \%$ dos gêneros (Garcia \& Dutra 2004), confirmando a sua importância florística.

Neste trabalho é apresentado o estudo florístico de Papilionoideae no PNSC incluindo chaves analíticas, descrições e comentários sobre distribuição geográfica.

\section{Material e métodos}

O Parque Nacional da Serra da Canastra está situado no sudoeste do estado de Minas Gerais $\left(20^{\circ} 00^{\prime}-20^{\circ} 30^{\prime} \mathrm{S}\right.$ e $\left.46^{\circ} 15^{\prime}-47^{\circ} 00^{\prime} \mathrm{W}\right)$ abrangendo parte dos municípios de São Roque de Minas, Sacramento e Delfinópolis, em uma área de 71.525 ha, com altitudes variando de 800-1.200 m e chegando a 1.496 m, no local denominado Serra Brava (Romero \& Nakajima 1999). As principais fitofisionomias encontradas são as florestas mesófilas de encosta, capões, cerradão, cerrado sensu stricto, campo cerrado, campo limpo, além dos campos rupestres (IBDF 1981).

A coleta do material botânico foi realizada entre 1994 e 2001 como parte do projeto "Flora do Parque Nacional da Serra da Canastra" coordenado pela Universidade Federal de Uberlândia. As duplicatas de Papilionoideae amostradas foram doadas e depositadas no Herbário VIC, do Departamento de Biologia Vegetal da Universidade Federal de Viçosa, para o desenvolvimento do presente estudo.
Os termos morfológicos utilizados nas descrições dos táxons foram baseados na literatura taxonômica sobre a subfamília e nos trabalhos de Radford et al. (1974) e Polhill \& Raven (1981); os tipos de inflorescências em Radford et al. (1974) e os tipos de frutos em Barroso et al. (1999). A classificação adotada para tribos e gêneros foi a de Lewis et al. (2005).

As chaves para a identificação dos táxons, bem como as descrições, foram elaboradas apenas com base no material coletado no PNSC, sendo os táxons apresentados em ordem alfabética. Dados sobre a distribuição geográfica dos táxons foram obtidos a partir de revisões dos gêneros estudados e do International Legume Database \& Information Service (ILDIS 2005).

\section{Resultados e Discussão}

O levantamento florístico de Papilionoideae no PNSC totalizou 41 espécies, reunidas em 23 gêneros e oito tribos. A riqueza da subfamília no PNSC foi equivalente à obtida em outras áreas de campos rupestres em Minas Gerais, como por exemplo, em Grão Mogol, onde Papilionoideae reuniu 44 espécies em 23 gêneros (Queiroz 2004). As tribos mais expressivas foram Phaseoleae, com nove gêneros (Camptosema (1), Centrosema (2), Clitoria (1), Collaea (2), Eriosema (3), Erythrina (1), Galactia (5), Periandra (2) e Vigna (3) e Dalbergieae, com sete gêneros (Andira (3), Dalbergia (1), Machaerium (1), Platypodium (1), Poiretia (1), Stylosanthes (2) e Zornia (3). Sophoreae foi representada por Acosmium (1) e Bowdichia (1), enquanto que as demais tribos contaram com apenas um gênero: Crotalarieae (Crotalaria, 2), Desmodieae (Desmodium, 1), Genisteae (Lupinus, 2), Millettieae (Platycyamus, 1) e Swartzieae (Swartzia, 1). Quanto ao hábito, a maioria das espécies $(63 \%)$ faz parte do estrato herbáceo (ervas eretas ou prostradas, subarbustos e trepadeiras), apenas 10 espécies (24\%) são arbóreas.

Chave para os gêneros de Papilionoideae ocorrentes no PNSC

1. Folhas paripinadas ou bifolioladas

2. Estípulas prolongadas abaixo do ponto de inserção; inflorescência espiciforme; fruto lomento

2. Estípulas não prolongadas abaixo do ponto de inserção; inflorescência racemosa; fruto legume 19. Poiretia

1. Folhas imparipinadas, uni ou trifolioladas 
3. Folhas unifolioladas

4. Androceu monadelfo, anteras dimórficas

5. Folíolos lineares, lanceolados, elípticos ou elíptico-lanceolados; corola roxo-azulada; legume plano

14. Lupinus

5. Folíolos oblongos ou obovados; corola amarela a amarelo-alaranjada; legume inflado

8. Crotalaria

4. Androceu diadelfo, anteras isomórficas

6. Folíolos com glândulas puntiformes amarelas; cálice 5-laciniado

11. Eriosema

6. Folíolos sem glândulas puntiformes amarelas; cálice 4-laciniado

13. Galactia

3. Folhas 3-plurifolioladas

7. Estipelas presentes

8. Folhas 3-folioladas

9. Árvores

10. Estipelas glandulares; corola avermelhada

12. Erythrina

10. Estipelas não glandulares; corola lilás a púrpura

17. Platycyamus

9. Arbustos, subarbustos, ervas, trepadeiras e lianas

11. Cálice 4-mera

12. Lianas; cálice tubuloso; ovário estipitado

4. Camptosema

12. Subarbustos ou ervas; cálice campanulado; ovário séssil

13. Galactia

11. Cálice 5-mera

13. Corola ressupinada

14. Raque foliar 0,2-2 cm compr.; cálice bilabiado ou campanulado; vexilo

2-3 cm compr.; ovário subséssil

15. Trepadeiras ou ervas prostradas

5. Centrosema

15. Arbustos ou subarbustos 16. Periandra

14. Raque foliar ausente; cálice tubuloso; vexilo ca. 5,7 cm compr.; ovário estipitado

6. Clitoria

13. Corola não ressupinada

16. Subarbusto; inflorescência terminal, ca. 18-flora; botão floral reto; fruto lomento

10. Desmodium

16. Trepadeira; inflorescência axilar, 3-9-flora; botão floral curvo; fruto legume

22. Vigna

8. Folhas plurifolioladas

17. Raque foliar cilíndrica; fruto drupa

2. Andira

17. Raque foliar marginada; fruto legume

21. Swartzia

7. Estipelas ausentes

18. Folhas 3-5(-7)- folioladas

19. Árvores; corola actinomorfa

1. Acosmium

19. Ervas, subarbustos e arbustos; corola zigomorfa

20. Raque foliar 2-10 mm compr.; folíolos com glândulas puntiformes amarelas na face abaxial; cálice 5-laciniado

11. Eriosema

20. Raque foliar ausente; folíolos sem glândulas puntiformes amarelas; cálice

4-laciniado

21. Estípulas amplexicaules, persistentes; corola amarela; androceu monadelfo, anteras dimórficas; fruto lomento 20. Stylosanthes

21. Estípulas não amplexicaules, caducas; corola branca ou avermelhada; androceu diadelfo, anteras isomórficas; fruto legume

7. Collaea

18. Folhas 9-25-folioladas 
22. Face abaxial dos folíolos serícea; androceu dialistêmone; fruto legume samaróide 3. Bowdichia

22. Face abaxial dos folíolos glabrescente, tomentosa ou vilosa; androceu monadelfo ou poliadelfo; fruto sâmara

23. Folíolos com ápice emarginado, face abaxial tomentosa; androceu poliadelfo; região seminífera distal 18. Platypodium

23. Folíolos com ápice arredondado ou agudo, face abaxial glabrescente ou vilosa; androceu monadelfo; região seminífera central ou proximal

24. Folíolos 1,2-3,1 cm compr., ápice arredondado, glabrescentes; sâmara com região seminífera central 9. Dalbergia

24. Folíolos 5,5-7,8 cm compr., ápice agudo, vilosos; sâmara com região seminífera proximal 15. Machaerium

1. Acosmium Schott, Syst. Veg. (ed.16) 4: 406. 1827.

1.1. Acosmium dasycarpum (Vogel) Yakovlev ssp. dasycarpum, Notes Roy. Bot. Gard. Edinburgh 29: 351. 1969.

Figura 1a

Árvores, 2,5-3 m alt. Estípulas lanceoladas, ca. $3 \mathrm{~mm}$ compr., caducas; estipelas ausentes. Folhas imparipinadas, 3-5(-7) folioladas; pecíolo 2,5-3,3(-3,8) cm compr., lanuginoso; raque (2,3-) 4,5$6,6 \mathrm{~cm}$ compr., lanuginosas; folíolos (3,3-)4,2-8,5× 2-4 cm, elípticos, base obtusa, raro oblíqua, ápice retuso, face adaxial ciliada, face abaxial lanuginosa, dourada. Inflorescências paniculadas, 7,1-9,5 cm compr., axilares, terminais, ca. 100-flora; cálice 5-laciniado, campanulado, ca. $5 \mathrm{~mm}$ compr., esparsamente lanuginoso; corola actinomorfa, amareloalaranjada, pétalas ca. $3,5 \times 5 \mathrm{~mm}$, glabras; androceu dialistêmone, 10 estames, ca. 9 mm compr., anteras isomórficas; ovário estipitado, ca. $5 \mathrm{~mm}$ compr.; lanuginoso. Frutos não observados.

Material examinado: BRASIL. Minas Gerais: São Roque de Minas, PNSC, guarita de Sacramento, 18-XI-1995, fl., Romero et al. 3110 (HRCB).

Restrita ao Brasil (Yakovlev 1969, ILDIS 2005) ocorre em Minas Gerais, Rio de Janeiro, São Paulo (Yakovlev 1969) e Bahia (Lewis 1987). Ocupa áreas de cerrado (Mendonça et al. 1998, Filardi 2005) e campos rupestres da Cadeia do Espinhaço (Giulietti et al. 1987, Zappi et al. 2003), sendo encontrada, no PNSC, em cerrado com evidências de queimada.

2. Andira Juss., Gen. P1.: 363. 1789.

1. Subarbustos, 0,1-0,3 m alt. 2.2. A. humilis

1. Árvores, 5-6 m alt.
2. Folíolos com ápice obtuso, face abaxial esparsamente tomentosa a glabrescente ................2.1. A. fraxinifolia

2. Folíolos com ápice retuso, face abaxial densamente tomentosa 2.3. A. vermifuga

2.1. Andira fraxinifolia Benth., Comm. Legum. Gen. 44. 1837.

Figura $1 \mathrm{~b}$

Árvores, ca. $6 \mathrm{~m}$ alt. Estípulas lanceoladas, 2-9 mm compr., caducas; estipelas presentes. Folhas imparipinadas, 7-11-folioladas; pecíolo 22-45 mm compr., tomentoso; raque 4,7-12 cm compr., tomentosa, cilíndrica; folíolos (3,5-)5,4-8,5×2,2-3,7 cm, obovados, oblongo-elípticos, base cuneada, ápice obtuso, face adaxial glabra, face abaxial esparsamente tomentosa a glabrescente. Flores não observadas. Drupas imaturas ca. $2,9 \times 2,5 \mathrm{~cm}$, orbiculares, glabras; sementes globosas a alongadas, castanhas.

Material examinado: BRASIL. Minas Gerais: São Roque de Minas, PNSC, cachoeira da Casca D'Anta, parte baixa, 19-X-1994, fr., Nakajima et al. 607 (HRCB, HUFU).

Restrita ao Brasil, apresenta ampla distribuição (Pernambuco, Alagoas, Ceará, Bahia, Distrito Federal, Goiás, Espírito Santo, Minas Gerais, Rio de Janeiro, São Paulo, Paraná, Santa Catarina), ocorrendo em áreas de mata atlântica, em restinga e no cerrado, inclusive em áreas de campos rupestres (Pennington 2003). No PNSC, a espécie foi coletada em mata ciliar.

2.2. Andira humilis Mart. ex Benth., Comm. Legum. Gen. 45. 1837.

Figura 1c-d 
Subarbustos com xilopódio, raro arbustos, 10-30 cm alt. Estípulas setáceas, ca. 2-7 mm compr., persistentes; estipelas presentes. Folhas imparipinadas, 9-15 folioladas; pecíolo 1,5-3,5 mm compr., glabrescente; raque 6-9,5 cm compr., glabrescente, cilíndrica; folíolos (5-)7,5-11×2,5-3,7 cm, elípticos a estreitamente elípticos, base obtusa, ápice obtuso, retuso, glabros. Inflorescências paniculadas, $10-30 \mathrm{~cm}$ compr., terminais, mais de 100-flora, botão floral reto; cálice 5-laciniado, campanulado, ca. $7 \mathrm{~mm}$ compr., externamente seríceo; corola zigomorfa, rosa a púrpura, vexilo $9-12 \times 10-12 \mathrm{~mm}$, glabro, alas 12-14×4-5 mm, pétalas da carena 9-12×4-6 $\mathrm{mm}$; androceu monadelfo, 10 estames, ca. $12 \mathrm{~mm}$ compr., anteras isomórficas; ovário estipitado, ca. $1 \mathrm{~cm}$ compr., glabro. Drupas ca. $5 \times 3,5 \mathrm{~cm}$, ovóides, glabras; sementes globosas a alongadas, castanhas.

Materiais examinados: BRASIL. Minas Gerais: São Roque de Minas, PNSC, estrada para o Retiro das Pedras, 27-IX-1995, fl., Romero et al. 2867 (HRCB, HUFU, VIC); guarita de Sacramento, 24-IX-1995, fl., Romero et al. 2731 (HRCB, HUFU, VIC); 2757 (HRCB, HUFU, VIC); 18-XI-1995, fl., Romero et al. 3078 (HRCB, HUFU, VIC); posto de observação na estrada para Sacramento, 27-IX-1995, fl., Romero et al. 2906 (HRCB, HUFU, VIC); torre de observação, 11-I-1998, fr., Romero et al. 4997 (HUFU, VIC).

Presente no Paraguai e no Brasil, onde ocorre em formações abertas e ao longo do cerrado, nos estados do Pará, Maranhão, Rio Grande do Norte e Pernambuco, e na região Centro-Oeste até o Paraná (Pennington 2003), incluindo áreas de campo rupestre da Cadeia do Espinhaço (Gavilanes \& Brandão 1991). No PNSC, ocorre nas fitofisionomias de campo cerrado e em campos limpos com afloramentos rochosos.

2.3. Andira vermifuga Mart. ex Benth., Comm. Legum. Gen. 44. 1837.

Figura 1e

Árvores, ca. $5 \mathrm{~m}$ alt. Estípulas lanceoladas, ca. $4 \mathrm{~mm}$ compr., caducas; estipelas presentes. Folhas imparipinadas, 9-11-folioladas; pecíolo 38-42 mm compr., tomentoso; raque 10-12,5 cm compr., tomentosa, cilíndrica; folíolos (4-)5,5-8,2×2,6-4,4 cm, elípticos, oblongo-elípticos, base truncada a cuneada, ápice retuso, face adaxial glabra, face abaxial densamente tomentosa. Inflorescências paniculadas, ca. 20 cm compr., terminais, mais de 100-flora; botão floral reto; cálice 5-laciniado, cilíndrico-campanulado, 6-7 mm compr., esparsamente seríceo; corola zigomorfa, lilas a púrpura, vexilo 9-10×9-12 mm, glabro, alas $8-9 \times 4-5 \mathrm{~mm}$, pétalas da carena 7-8 $\times 4-5 \mathrm{~mm}$; androceu monadelfo, 10 estames, 12-14 mm compr.; anteras isomórficas; ovário estipitado, ca. $4 \mathrm{~mm}$ compr., glabro. Frutos não observados.

Material examinado: BRASIL. MinAs GerAIs: São Roque de Minas, PNSC, Chapadão do Diamante, 22-IX-1996, fl., Romero \& Nakajima 3624 (HUFU, VIC).

Restrita à América do Sul, ocorre no Peru, Bolívia e Brasil, onde ocupa áreas de cerrado e formações ribeirinhas, principalmente, nas regiões Norte e Nordeste, do Planalto Central até Minas Gerais e São Paulo (Pennington 2003). No PNSC, a espécie foi coletada em borda de mata limítrofe a campos rupestres.

3. Bowdichia Kunth, Nov. Gen. Sp. 6: 295. 1823.

3.1. Bowdichia virgilioides Kunth, Nov. Gen. Sp. 6: 376-377. 1823.

Árvores, 4-6 m alt. Estípulas ovadas, 4-5 mm compr., caducas; estipelas ausentes. Folhas imparipinadas, 9-17 folioladas; pecíolo 1,4-2,9 cm compr., tomentoso; raque $8,8-9,8 \mathrm{~cm}$ compr., tomentosa; folíolos 3-5,5×0,8-1,6 cm, oblongos, base obtusa, ápice retuso, face adaxial glabrescente, face abaxial serícea. Inflorescências paniculadas, $13-15 \mathrm{~cm}$ compr., terminais, ca. 100-flora, botão floral reto; cálice 5-laciniado, campanulado, ca. $15 \mathrm{~mm}$ compr., puberulento; corola zigomorfa, roxa, vexilo ca. $18 \times 18 \mathrm{~mm}$ compr., glabro, alas ca. $22 \times 10 \mathrm{~mm}$, pétalas da carena ca. $15 \times 5 \mathrm{~mm}$; androceu dialistêmone, ca. $8 \mathrm{~mm}$ compr., anteras isomórficas; ovário estipitado, ca. $8 \mathrm{~mm}$ compr., puberulento. Legumes samaróides 4,5-6×1-1,5 cm, oblongos, ca. 2 mm larg., glabros; sementes ovais, alaranjadas a amarelas.

Materiais examinados: BRASIL. MinAs GeraIs: São Roque de Minas, PNSC, cachoeira da Casca D'Anta parte baixa, 29-IX-1995, fl. fr., Nakajima et al. 1405 (HRCB, HUFU, VIC); cachoeira dos Rolinhos parte alta, 21-IX-1996, fl., Nakajima et al. 2068 (HUFU, VIC), guarita 1, 19-X-1994, fr., Nakajima \& Romero 261 (HRCB, HUFU).

Material adicional examinado: BRASIL. MinAS GeRAIS: Mariana, Parque Estadual do Itacolomi, estrada do 
Cibrão, 26-IX-2005, fl., Lima \& Garcia 388 (VIC).

Ocorre na Bolívia, Colômbia, Guiana, Paraguai, Suriname, Venezuela e Brasil (ILDIS 2005), onde pode ser encontrada em formações de restinga (Lewis 1987) e comumente no cerrado (Sakuragui et al. 2004, Filardi 2005), sendo também citada para campos rupestres da Cadeia do Espinhaço (Giulietti et al. 1987, Gavilanes \& Brandão 1991, Zappi et al. 2003). No PNSC, B. virgilioides ocorre em áreas de mata próximas a cursos d'água e em campos rupestres.

4. Camptosema Hook. \& Arn., Bot. Misc. 3: 200. 1833.

4.1. Camptosema scarlatinum (Mart. ex Benth.) Burkart, Darwiniana 16: 199. 1970.

Figura 1f-h

Lianas. Estípulas lanceoladas, 2-5 mm compr., persistentes; estipelas presentes. Folhas 3-folioladas; pecíolo $(0,8-) 1,2-5(-7) \mathrm{cm}$ compr., tomentoso; raque 2-4 mm compr., tomentosa; folíolos (3-)4,5-7,5(-9,5)× 2-3,2(-3,8) cm, elípticos a lanceolados, base obtusa, ápice agudo, mucronulado, face adaxial glabra, face abaxial puberulenta, serícea na nervura principal. Inflorescências racemosas, nodosas, ca. 6-18 cm compr., axilares, 4-10-flora, botão floral reto; cálice 4-laciniado, tubuloso, 17-27 mm compr., viloso; corola zigomorfa, vermelho-vinácea, vexilo 16-22×9-12 mm, glabro, alas $15-20 \times 3 \mathrm{~mm}$, pétalas da carena $13-19 \times$ 3-4 mm; androceu pseudomonadelfo, 10 estames, ca. $2 \mathrm{~cm}$ compr., anteras isomórficas; ovário estipitado, ca. 8,5 mm compr., puberulento. Legumes $23-50 \times$ 5-7 mm, lineares, tomentosos; sementes compressas, ovadas, castanhas.

Materiais examinados: BRASIL. MinAs Gerais: São Roque de Minas, PNSC, cachoeira da Casca D'Anta, encosta da Chapada, 17-VII-1995, fl. fr., Romero et al. 2547 (HRCB, HUFU, VIC); cachoeira dos Rolinhos, 21-IX-1996, fl., Nakajima et al. 2047 (HUFU, VIC); 21-VIII-1997, fl., Romero et al. 4460 (HUFU, VIC); estrada para o Retiro das Pedras, 14-V-1995, fl. fr., Romero et al. 2314 (HRCB, HUFU, VIC); 18-VII-1995, fl., Nakajima et al. 1230 (HRCB, HUFU, VIC); 20-II-1997, fl., Nakajima et al. 2186 (HUFU, VIC); guarita da Casca D'Anta, parte de baixo, 26-VI-1997, fl., Nakajima et al. 2599 (HUFU, VIC); Vale dos Cândidos, próximo ao Córrego das Posses, 27-VI-1997, fl., Romero et al. 4303 (HUFU, VIC).
Ocorre na Argentina, Paraguai e Brasil, onde distribui-se da região Centro-Oeste até o Rio Grande do Sul, em formações campestres e bordas de mata (Burkart 1970), sendo expressiva nos campos rupestres da Cadeia do Espinhaço (Harley \& Simmons 1986, Giulietti et al. 1987, Pirani et al. 1994, Brandão et al. 1995, Lewis 1995, Dutra 2005). No PNSC, a espécie foi encontrada em formações de campos limpos, campos sujos e em bordas de mata.

5. Centrosema (DC.) Benth., Comm. Legum. Gen. 53-54. 1837.

1. Folíolos 1,6-4,3×0,5-1,5 cm; inflorescência $0,6-2$ cm compr.; corola violácea 5.1. C. brasilianum

1. Folíolos 5-7,5×2,5-3,7 cm; inflorescência ca. $4 \mathrm{~cm}$ compr.; corola lilás e branca ..... 5.2. C. pubescens

5.1. Centrosema brasilianum (L.) Benth., Comm. Legum. Gen. 54. 1837.

Figura 1i

Trepadeiras ou ervas prostradas. Estípulas lanceoladas, 3-4 mm compr., persistentes; estipelas presentes. Folhas 3-folioladas; pecíolo 7-42 mm compr., puberulento; raque 2-10 $\mathrm{mm}$, glabrescente; folíolos 1,6-4,3×0,5-1,5 cm, obtusos, base obtusa, ápice agudo, puberulentos a glabrescentes. Inflorescências racemosas, 6-20 mm compr., axilares, 1-3-flora, botão floral reto; cálice 5-laciniado, bilabiado, ca. $9 \mathrm{~mm}$ compr., glabrescente; corola zigomorfa, violácea, ressupinada, vexilo ca. $2 \times 2 \mathrm{~cm}$, seríceo, alas ca. $14 \times 4 \mathrm{~mm}$, pétalas da carena ca. $16 \times 4 \mathrm{~mm}$; androceu diadelfo, 9+1 estames, ca. 16 mm compr., anteras isomórficas; ovário subséssil, ca. $4 \mathrm{~mm}$ compr., puberulento a glabrescente. Legumes $7-10 \times 0,5 \mathrm{~cm}$, lineares, transversalmente reticulados, puberulentos a glabrescentes; sementes oblongas, castanho-escuras.

Materiais examinados: BRASIL. MinAs Gerais: São Roque de Minas, PNSC, estrada da Fazenda do Fundão, 19-IV-1997, fl. fr., Romero et al. 4195 (HUFU, VIC); estrada de Sacramento após entrada para Casca D'Anta, 11-I-1995, fl., Romero et al. 1735 (HRCB, HUFU, VIC); estrada de Sacramento, $25 \mathrm{~km}$ da guarita, 22-III-1995, fl., Nakajima et al. 953 (HRCB, HUFU, VIC); estrada de Sacramento, $35 \mathrm{~km}$ da Sede Administrativa, 22-II-1994, fl. fr., Romero et al. 690 (HRCB, HUFU, VIC); mata próxima a 
cachoeira dos Rolinhos, 23-II-1997, fl., Romero et al. 3996 (HUFU, VIC).

Espécie de ampla distribuição na América do Sul (Williams \& Clements 1990). No Brasil, ocorre nos estados das regiões Norte e Nordeste, em Minas Gerais e Mato Grosso (Queiroz et al. 2004), ocupando áreas de cerrado, caatinga, restinga e associadas a cursos d'água (Barbosa-Fevereiro 1977), bem como campos rupestres da Cadeia do Espinhaço (Brandão et al. 1995, Lewis 1995, Zappi et al. 2005). No PNSC, ocorre em formações de campo limpo, de campo cerrado e em borda de mata.

5.2. Centrosema pubescens Benth., Comm. Legum. Gen. 55. 1837.

\section{Figura $1 \mathrm{j}-\mathrm{k}$}

Trepadeiras. Estípulas ovadas, 2-4 mm compr., persistentes; estipelas presentes. Folhas 3-folioladas; pecíolo 9-42 mm compr., tomentoso; raque 5-20 mm compr., glabrescente; folíolos 5-7,5×2,5-3,7 cm, ovadolanceolados a elíptico-obovados, base obtusa, ápice agudo, face adaxial glabrescente, face abaxial puberulenta a glabrescente. Inflorescências pseudoracemosas, ca. $4 \mathrm{~cm}$ compr., axilares, 2-3-flora, botão floral reto; cálice 5-laciniado, bilabiado, ca. $9 \mathrm{~mm}$ compr., puberulento; corola zigomorfa, lilás e branca, ressupinada; vexilo ca. $3 \times 3,6 \mathrm{~cm}$, seríceo, alas ca. $17 \times 5 \mathrm{~mm}$, pétalas carena ca. $18 \times 6 \mathrm{~mm}$; androceu diadelfo, 9+1 estames, ca. $2 \mathrm{~cm}$ compr., anteras isomórficas; ovário subséssil, ca. $6 \mathrm{~mm}$ compr., seríceo. Legumes 15-20×0,5-0,6 cm, lineares, seríceos a glabrescentes; sementes oblongas, negras.

Materiais examinados: BRASIL. MinAs GeraIs: São Roque de Minas, PNSC, cachoeira de Rolinhos parte baixa, 29-VI-1997, fr., Romero et al. 4366 (HUFU, VIC); estrada para o Retiro das Pedras, 14-V-1995, fr., Romero et al. 2315 (HRCB, HUFU, VIC); 20-II-1997, fl., Nakajima et al. 2189 (HUFU, VIC).

Restrita ao Brasil, ocorre nas regiões Norte, Nordeste e Sudeste, em formações campestres ou florestais, preferencialmente em lugares úmidos (Barbosa-Fevereiro 1977). No PNSC, foi coletada em áreas de mata, beira de córrego e em campo limpo.

6. Clitoria L., Sp. P1. 2: 753. 1753.

6.1. Clitoria guianensis (Aubl.) Benth., J. Proc. Linn.

Soc., Bot. 2: 40. 1858.

Figura 11
Ervas eretas, prostradas ou subarbustos, 20-40 cm alt. Estípulas triangulares, 5-7 mm compr., persistentes; estipelas presentes. Folhas 3 -folioladas; pecíolo 8-18 mm compr., densamente tomentoso a glabrescente; raque ausente; folíolos 6-16×0,6-1,6 cm, oblongos, base aguda, ápice agudo, mucronado, face adaxial glabrescente, face abaxial esparsamente vilosa. Inflorescências pseudoracemosas, 7-7,3 cm compr., axilares, 1-2-flora, botão floral reto; cálice 5-laciniado, tubuloso, 2,4-3,5 cm compr., esparsamente viloso; corola zigomorfa, branco-violácea, ressupinada, vexilo ca. $5,7 \times 4,8 \mathrm{~cm}$, glabro, alas ca. $4,5 \times 1 \mathrm{~cm}$, pétalas da carena ca. $4 \times 1 \mathrm{~cm}$; androceu diadelfo, 9+1 estames, ca. $4 \mathrm{~cm}$ compr., anteras isomórficas; ovário estipitado, ca. 1,2 cm compr, glabro. Frutos não observados.

Materiais examinados: BRASIL. MinAs GERAIS: São Roque de Minas, PNSC, estrada para o Retiro das Pedras, 10-XII-1994, fl., Romero et al. 1544 (HRCB, HUFU, VIC); estrada para Sacramento, 8-XII-1994, fl., Romero et al. 1520 (HRCB, HUFU, VIC); estrada para a Serra da Chapada, 14-X-1997, fl., Romero et al. 4581 (HUFU, VIC); Serra das Sete Voltas, 25-IX-1996, fl., Romero et al. 3726 (HUFU, VIC); guarita de Sacramento, 14-X-1994, fl., Romero et al. 1254 (HRCB, HUFU, VIC); torre de Observação, estrada para a divisa do Parque, 17-X-1997, fl., Nakajima et al. 2934 (HUFU, VIC).

Apresenta ampla distribuição, ocorrendo no México, Caribe, América Central e América do Sul (ILDIS 2005). No Brasil, a espécie pode ser encontrada desde a região Norte até a Sudeste, no Estado de São Paulo, ocupando formações campestres de cerrado (Mimura et al. 2004) e campos rupestres da Cadeia do Espinhaço (Giulietti et al. 1987, Gavilanes et al. 1995). No PNSC, foi encontrada em áreas de campo limpo, campo cerrado e cerrado sensu stricto.

7. Collaea DC., Ann. Sci. Nat. (Paris) 4: 96. 1825.

1. Folhas sésseis; face abaxial dos folíolos lanuginosa; corola branca 7.2. C. stenophylla

1. Folhas pecioladas, pecíolos 2-4 $\mathrm{mm}$ compr.; face abaxial dos folíolos serícea; corola avermelhada .......... 7.1. C. speciosa

7.1. Collaea speciosa (Loisel.) DC., Mem. Legum. 6:245. 1825.

Figura 1m-n 
Arbustos, subarbustos, 0,5-1,7 m alt. Estípulas não observadas, caducas; estipelas ausentes. Folhas 3-folioladas; pecíolo 2-4 mm compr., tomentoso; raque ausente; folíolos 4,1-10,6×(0,6-)1-2,2 cm, oblanceolados a estreitamente elípticos, base atenuada, ápice obtuso a agudo, mucronulado, face adaxial glabra, face abaxial serícea. Inflorescências pseudoracemosas, 5-7 cm compr., axilares, terminais, 4-12-flora, botão floral reto; cálice 4-laciniado, campanulado, 1,7-2 cm compr., tomentoso; corola zigomorfa, avermelhada, vexilo 27-34×15-22 mm, esparsamente seríceo, alas $27-33 \times 7-11 \mathrm{~mm}$, pétalas da carena 26-29×7-9 mm; androceu diadelfo, 9+1 estames, 28-31 mm compr.; anteras isomórficas; ovário séssil, ca. $15 \mathrm{~mm}$ compr., seríceo. Legumes ca. $5,5 \times 0,6 \mathrm{~cm}$, oblongos, seríceos; sementes não observadas.

Materiais examinados: BRASIL. MinAs Gerais: São Roque de Minas, PNSC, cachoeira dos Rolinhos, 26V-1996, fl., Nakajima \& Romero 1777 (HUFU, VIC); 29-VI-1997, fl. fr., Romero et al. 4367 (HUFU, VIC); nascente do córrego do Bárbaro, 24-VIII-1997, fl., Nakajima et al. 2782 (HUFU, VIC); vale dos Cândidos, 27-VI-1997, fl., Romero et al. 4305 (HUFU, VIC); 22-VIII-1997, fl. fr., Nakajima et al. 2751 (HUFU, VIC).

Apresenta ampla distribuição na América do Sul (Lewis 1987). No Brasil sua distribuição está associada ao cerrado, onde ocorre nas fitofisionomias de cerrado sensu stricto, cerradão e mata ciliar (Mendonça et al. 1998), sendo também citada para campos rupestres da Cadeia do Espinhaço (Giulietti et al. 1987, Gavilanes et al. 1995). No PNSC a espécie foi amostrada apenas na mata ciliar.

7.2. Collaea stenophylla (Hook. \& Arn.) Benth., Fl. Bras. 15(1B): 146. 1862.

Figura 1o

Arbustos, subarbustos eretos ou prostrados, 0,5-2 m alt. Estípulas não observadas, caducas; estipelas ausentes. Folhas 3-folioladas; sésseis; raque ausente; folíolos (3-)3,7-5,8×0,7-1,5 cm, oblanceolados, oblongos, elípticos, base atenuada, ápice obtuso, retuso, face adaxial puberulenta, face abaxial lanuginosa. Inflorescências pseudoracemosas, 2-5,5 cm compr., axilares, terminais, 8-16-flora, botão floral reto; cálice 4-laciniado, campanulado, ca. $1 \mathrm{~cm}$ compr., viloso a lanuginoso; corola zigomorfa, branca, vexilo ca. $17 \times 14 \mathrm{~mm}$, puberulento, alas ca. $14 \times 10 \mathrm{~mm}$, pétalas da carena ca. $14 \times 6 \mathrm{~mm}$; androceu diadelfo, 9+1 estames, ca. $16 \mathrm{~mm}$ compr.; anteras isomórficas; ovário séssil, ca. $7 \mathrm{~mm}$ compr., lanuginoso. Legumes 4,6-6×0,8-1,2 cm, oblongos, lanuginosos; sementes circulares, castanhas rajadas de negro.

Materiais examinados: BRASIL. MinAs Gerais: São Roque de Minas, PNSC, cachoeira dos Rolinhos, 21-XI-1995, fl., Nakajima et al. 1542 (HRCB, VIC); 12-I-1996, fl., Romero et al. 3277 (HRCB, HUFU); estrada para a fazenda do Fundão, 19-IV-1997, fl., Romero et al. 4196 (HUFU, VIC); 25-VI-1997, fl. fr., Romero et al. 4246 (HUFU, VIC); estrada para o Retiro das Pedras, 18-IV-1992, fl. fr., Castro 302 (HRCB, HUFU); 18-VII-1995, fl. fr., Nakajima et al. 1213 (HRCB, HUFU); 20-II-1997, fl. fr., Nakajima et al. 2188 (HUFU, VIC); 23-II-1997, fl., Romero et al. 3958 (HUFU, VIC); estrada para Sacramento, 19-IV-1994, fr., Nakajima et al. 310 (HRCB, HUFU); morro da guarita, 23-II-1994, fl., Nakajima \& Romero 181 (HRCB, HUFU).

Espécie restrita à América do Sul, ocorre na Argentina, Brasil, Paraguai e Uruguai (ILDIS 2005). Apresenta ampla ocorrência no PNSC, tanto em fitofisionomias florestais quanto em formações campestres.

\section{Crotalaria L., Sp. Pl. 2: 714-716. 1753.}

1. Estípulas ausentes; pecíolo $12-18 \mathrm{~mm}$ compr.; folíolos obovados .... 8.2. C. unifoliolata

1. Estípulas presentes; pecíolo $3-5 \mathrm{~mm}$ compr.; folíolos oblongos 8.1. C. breviflora

8.1. Crotalaria breviflora DC., Prodr. 2: 127. 1825. Figura 2a-b

Subarbustos, 0,8-1 m alt. Estípulas decurrentes, 2,5-6,8 cm compr., persistentes; estipelas ausentes. Folhas 1-folioladas, pecíolo 3-5 mm compr., seríceo; folíolos 3-7,5×1-2,5 cm, oblongos, base obtusa, ápice agudo, mucronado, seríceos. Inflorescências racemosas, 5,5-12 cm compr., axilares, 6-12-flora, botão floral reto; cálice 5-laciniado, campanulado, ca. $12 \mathrm{~mm}$ compr., seríceo; corola zigomorfa, amarela, vexilo $12-14 \times 8-12 \mathrm{~mm}$, seríceo, alas ca. $14 \times 3 \mathrm{~mm}$, pétalas da carena ca. $14 \times 6 \mathrm{~mm}$; androceu monadelfo, 10 estames, 7-9 mm compr., anteras dimórficas: 5 longas e basifixas alternadas com 5 menores e dorsifixas; ovário subséssil, 7-8 mm compr., glabro. Legumes $3-4 \times 1 \mathrm{~cm}$, oblongos, glabros, inflados; sementes reniformes, castanhas. 


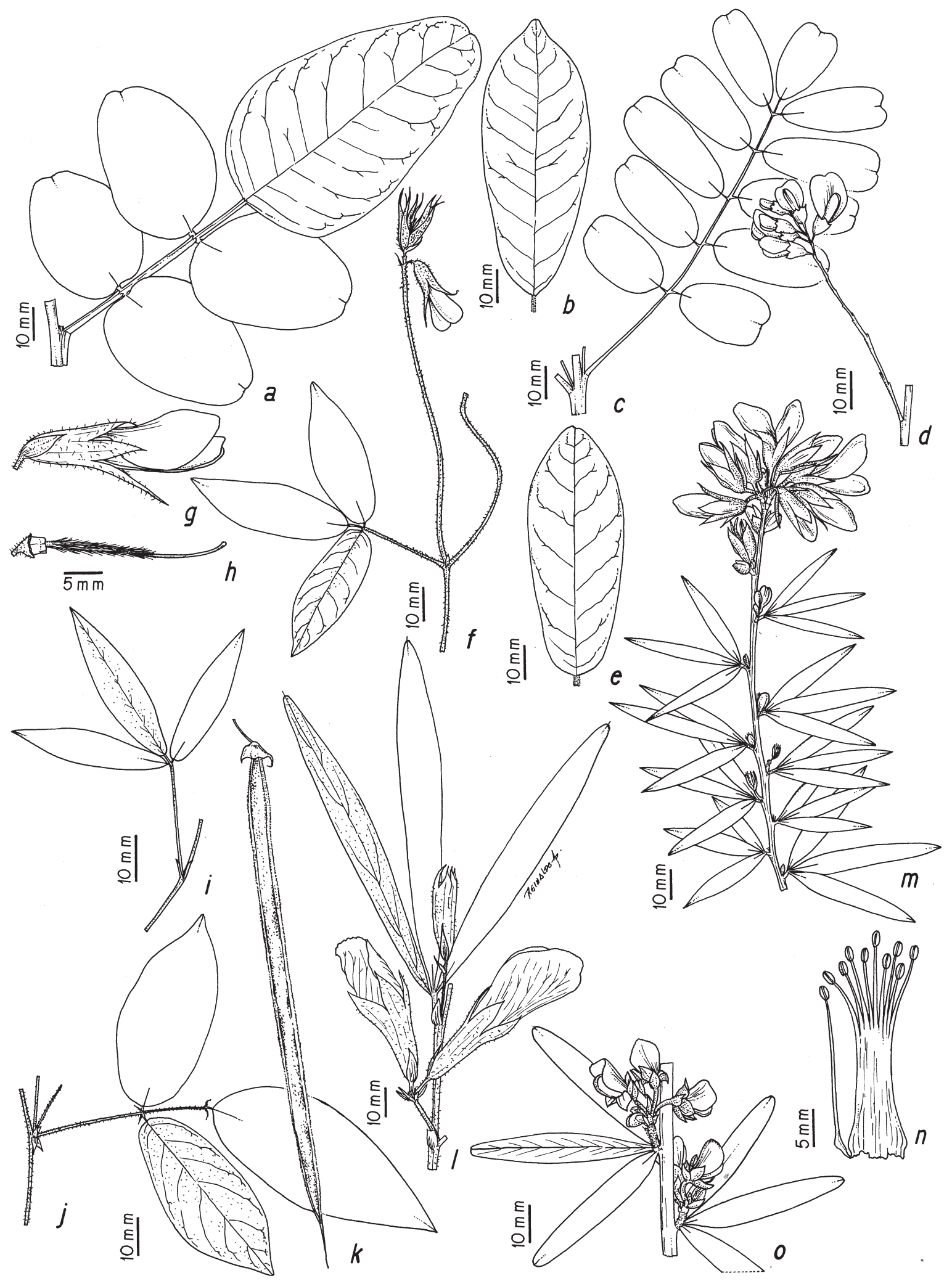

Figura 1. Acosmium dasycarpum ssp. dasycarpum. a. Folha (Romero et al. 3110). Andira fraxinifolia. b. Folíolo (Nakajima et al. 607). c-d. Andira humilis. c. Folha. d. Parte da inflorescência (Romero et al. 3078). Andira vermifuga. e. Folíolo (Romero \& Nakajima 3624). f-h. Camptosema scarlatinum. f. Ramo. g. Flor. h. Gineceu (Romero et al. 4303). Centrosema brasilianum. i. Folha (Romero et al. 4195). j-k. Centrosema pubescens. j. Folha. k. Legume (Romero et al. 2315). Clitoria guianensis. 1. Ramo (Romero \& Nakajima 1520). m-n. Collaea speciosa. m. Ramo. n. androceu (Nakajima \& Romero 1777). Collaea stenophylla. o. Ramo (Romero et al. 4196). 
Materiais examinados: BRASIL. MinAs Gerais: São Roque de Minas, PNSC, estrada do Retiro das Pedras, 14-V-1995, fl., Romero et al. 2281 (HRCB, HUFU, VIC); fl. fr., Romero et al. 2282 (HRCB, HUFU, VIC); 20-II-1997, fl., Nakajima et al. 2185 (HUFU, VIC); estrada para Sacramento, $25 \mathrm{Km}$ da guarita, 22-III-1995, fl. fr., Nakajima et al. 958 (HRCB, HUFU, VIC).

Citada para os estados de Goiás, Minas Gerais, Paraná, Rio de Janeiro, São Paulo, Mato Grosso e Paraíba (Windler \& Skinner 1981; Flores 2004), ocupando ambientes úmidos, próximos de cursos d'água no cerrado (Flores 2004) e campos rupestres da Cadeia do Espinhaço (Giulietti et al. 1987, Gavilanes et al. 1995, Lewis 1995). No PNSC, apresentou-se restrita às áreas de campo limpo.

8.2. Crotalaria unifoliolata Benth., Ann. Nat. Hist. 3: 430. 1839.

Ervas eretas, prostradas ou subarbustos, 20-40 cm alt. Estípulas e estipelas ausentes. Folhas 1-folioladas; pecíolo 1,2-1,8 cm compr., seríceo; folíolos 2,5-4×0,9-2 cm, obovados, base aguda, ápice obtuso, mucronulado, face abaxial puberulenta nas nervuras, face adaxial glabra. Inflorescências racemosas, 3,2-8 cm compr., terminais, ca. 14-flora, botão floral reto; cálice 5-laciniado, campanulado, 0,8-1 cm compr., puberulento; corola zigomorfa, amarelo-alaranjada, vexilo $1,3 \times 1-1,2 \mathrm{~cm}$ compr., seríceo, alas ca. $13 \times 3 \mathrm{~mm}$ compr., pétalas da carena $1-4 \times 5-6 \mathrm{~mm}$ compr.; androceu monadelfo, 10 estames, ca. $1 \mathrm{~cm}$ compr., anteras dimórficas: 5 longas e basifixas alternadas com 5 menores e dorsifixas; ovário subséssil, ca. $5 \mathrm{~mm}$ compr., esparsamente puberulento. Frutos não observados.

Materiais examinados: BRASIL. Minas Gerais: São Roque de Minas, PNSC, guarita de Sacramento, 9-I-1995, fl., Romero et al. 1597 (HRCB, HUFU, VIC); morro antes do Córrego dos Passageiros, 10-I-1998, fl., Romero et al. 4958 (HUFU, VIC); estrada para o Retiro das Pedras, 18-IV-1997, fl., Nakajima et al. 2381 (HUFU, VIC); estrada para Sacramento após o Curral de Pedras, 9-I-1998, fl., Romero et al. 4855 (HUFU, VIC); estrada para a Serra da Chapada, 8-I-1998, fl., Romero et al. 4809 (HUFU, VIC).

Restrita ao Brasil (ILDIS 2005), ocorre em Goiás e ao longo da Cadeia do Espinhaço (Bentham 1859). No PNSC, a espécie foi coletada em áreas de campo limpo, campo sujo e campo cerrado.

9. Dalbergia L. f., Suppl. P1. 52: 316. 1781.

9.1. Dalbergia miscolobium Benth., J. Linn. Soc. Bot. 4 (Suppl.): 35. 1860.

Figura 2c-d

Árvores, 2-3 m alt. Estípulas ovadas a subuladas, ca. $5 \mathrm{~mm}$ compr., caducas; estipelas ausentes. Folhas imparipinadas, 15-23 folioladas; pecíolo (7-)10-14 mm compr., glabro; raque 6,8-10,6 cm compr., glabrescente; folíolos $12-31 \times 6-15 \mathrm{~mm}$, oblongos, base cuneada, ápice arredondado, glabrescentes. Inflorescências paniculadas, 3,1-6,5 cm compr., axilares, terminais, pluri-flora, botão floral reto; cálice 5-laciniado, campanulado, 4-6 mm compr., ápice dos lobos ciliados; corola zigomorfa, roxa, vexilo $8 \times 5-8 \mathrm{~mm}$, glabro, alas ca. $7 \times 3 \mathrm{~mm}$, pétalas da carena ca. $6 \times 2 \mathrm{~mm}$; androceu monadelfo, 9-10 estames, 5-7 mm compr., anteras isomórficas; ovário estipitado, ca. $2 \mathrm{~mm}$ compr., glabro, tricomas estrigosos na base e lateral. Sâmaras 4,5-6×1,5-2 cm, oblongas, glabras, região seminífera central; sementes reniformes, compressas, negras.

Materiais examinados: BRASIL. MinAs Gerais: São Roque de Minas, PNSC, cachoeira da Casca D'Anta, encosta da parte baixa, 21-II-1997, fl. fr., Romero et al. 3898 (HUFU, VIC); guarita de Sacramento, 19-III-1995, fr., Romero et al. 2048 (HRCB, HUFU, VIC); morro da cachoeira da Casca D'Anta, 24-II-1994, fl., Romero et al. 727 (HRCB, HUFU, VIC); paredão da cachoeira da Casca D'Anta, 20-IV-1994, fr., Romero et al. 960 (HRCB, HUFU, VIC); 17-X-1994, fr., Nakajima et al. 556 (HRCB, HUFU, VIC).

Espécie restrita ao Brasil e característica do cerrado, ocorrendo do Piauí ao Paraná, sendo também citada para campos rupestres, em altitudes acima de 900 m (Carvalho 1997). No PNSC, ocorre em áreas de campo cerrado, campo rupestre e em cerrado sensu stricto.

10. Desmodium Desv., J. Bot. Agric. 1: 122. 1813.

10.1. Desmodium barbatum (L.) Benth., Pl. Jungh. 2: 224.1852.

Subarbustos eretos ou prostrados, ca. 0,5 m alt. Estípulas lanceoladas, 4-10 mm compr., persistentes; estipelas presentes. Folhas 3-folioladas, pecíolo 9-15 mm compr., esparsamente viloso; raque 2-3 mm 
compr., vilosa; folíolos 1-3,5×0,4-2 cm, ovados a obovados, base obtusa, ápice obtuso, mucronulado, face adaxial glabra, face abaxial vilosa. Inflorescências pseudo-racemosas, 2,4-5,2 cm compr., terminais, ca. 18-flora, botão floral reto; cálice 5-laciniado, campanulado, 4-7 mm compr., barbado; corola zigomorfa, violácea, vexilo 4-5×2-4 mm, glabro, alas 3,5-4,5×1,5 mm, pétalas da carena $3-4 \times 1 \mathrm{~mm}$; androceu diadelfo, 9+1 estames, ca. $4 \mathrm{~mm}$ compr., anteras isomórficas; ovário séssil, ca. $3 \mathrm{~mm}$ compr., velutino. Lomentos $10 \times 2-3 \mathrm{~mm}, 2$-4-articulados, margem superior reta, margem inferior sinuosa, pubérulos, tricomas uncinados; sementes oblongas, castanho-claras.

Materiais examinados: BRASIL. MinAs GeRAIS: São Roque de Minas, PNSC, estrada para o Retiro das Pedras, próximo à divisa do Parque, 23-II-1997, fl., Romero et al. 3973 (HUFU, VIC); morro próximo à Sede Administrativa, 19-II-1997, fl. fr., Romero et al. 3860 (HUFU, VIC).

Ocorre na América do Sul tropical e subtropical estando amplamente distribuída no Brasil, em diversos tipos de vegetação (Ducke 1949, 1954, Azevedo 1981), inclusive em campos rupestres da Cadeia do Espinhaço (Gavilanes \& Brandão 1991, Dutra 2005). No PNSC, foi coletada em áreas de campo limpo e de campo rupestre.

11. Eriosema (DC.) Rchb., Ann. Sci. Nat. (Paris) 9: 421.1826.

1. Folhas 1-folioladas

1. Folhas 3-folioladas

2. Folíolos com base subcordada ou cordada, esparsamente vilosos; inflorescência 2-4, 8 cm compr., 37-flora; estames ca. $0,9 \mathrm{~cm}$ compr. 11.1. E. campestre var. campestre

2. Folíolos com base aguda, densamente vilosos; inflorescência 10$20 \mathrm{~cm}$ compr., 9-12-flora; estames ca. $1,6 \mathrm{~cm}$ compr. 11.3. E. prorepens

11.1. Eriosema campestre Benth. var. campestre, Fl. Bras. 15(1B): 212. 1862.

Figura 2e-g

Ervas eretas ou prostradas, 0,1-0,25 m alt. Estípulas lanceoladas, (7-)8-20 mm compr., livres, persistentes; estipelas ausentes. Folhas 3-folioladas; pecíolo 2-5 mm compr., esparsamente viloso; raque
2-6 mm compr., esparsamente vilosa; folíolos 2,5-8 $\times 0,8-2,7 \mathrm{~cm}$, oblongos, obovados, base subcordada ou cordada, ápice obtuso, mucronulado, esparsamente vilosos, face abaxial com glândulas puntiformes amarelas. Inflorescências racemosas, 2-4,8 cm compr., axilares, 3-7-floras, botão floral reto; cálice 5-laciniado, campanulado, 8-13 mm compr., viloso, glândulas puntiformes amarelas; corola zigomorfa, amarelo-alaranjada; vexilo 10-15× 6,5-7 mm, puberulento, com tricomas glandulares, alas 11-12×2-2,5 mm, pétalas da carena 10-11×2,5-3 mm; androceu diadelfo, 9+1 estames, ca. $9 \mathrm{~mm}$ compr., anteras isomórficas; ovário subséssil, 3-4 mm compr., velutino. Legumes 12-20×7-8 mm, ovados, compressos, vilosos; sementes ovadas, castanhas a negras.

Materiais examinados: BRASIL. MinAs GERAIS: São Roque de Minas, PNSC, cachoeira dos Rolinhos, 21-II-1995, fl. fr., Nakajima et al. 1549 (HRCB, HUFU, VIC); Curral de Pedras, estrada para Sacramento, 18-X-1994, fl., Romero et al. 1311 (HRCB, HUFU, VIC); estrada para Sacramento, entrada para a Garagem de Pedras, 16-X-1997, fl., Romero et al. 4654 (HUFU, VIC); guarita de Sacramento, 18-XI-1995, fl., Romero et al. 3077 (HRCB, HUFU, VIC); guarita de Sacramento, caminho para o Córrego dos Coelhos, 23-IX-1996, fl., Romero et al. 3669 (HUFU, VIC); morro após o Vale do São Francisco, córrego da Fazenda, 26-IX-1995, fl., Romero et al. 2769 (HRCB, HUFU, VIC).

Ocorre no Paraguai e no Brasil, principalmente, em formações campestres entre 790-1.000 m de altitude, nos estados de Minas Gerais, São Paulo, Paraná, Santa Catarina (Grear 1970) e Rio Grande do Sul (Miotto 1988). No PNSC, ocorre em áreas de campo limpo, campo sujo e campo rupestre.

11.2. Eriosema heterophyllum Benth., Linnaea 23: 520. 1849.

Figura 2h-1

Trepadeiras ou ervas prostradas. Estípulas lanceoladas, 5-8 mm compr., conatas, persistentes; estipelas ausentes. Folhas 1-folioladas; pecíolo 2-5 mm compr., híspido; folíolos 3-7,5×2,1-3,9 cm, ovados a subcordados, base cordada, ápice obtuso, mucronulado, face adaxial glabrescente, face abaxial seríceotomentosa, com glândulas puntiformes amarelas. Inflorescências racemosas, 4-12 cm compr., axilares, 8-15-flora, botão floral reto; cálice 5-laciniado, 
campanulado, ca. $6 \mathrm{~mm}$ compr., esparsamente viloso, com glândulas puntiformes amarelas; corola zigomorfa, amarela; vexilo $10-14 \times 8-11 \mathrm{~mm}$, puberulento, com glândulas puntiformes amarelas, alas $10-12 \times 4 \mathrm{~mm}$, pétalas da carena ca. $10 \times 4 \mathrm{~mm}$; androceu diadelfo, 9+1 estames, 11-13 mm compr., anteras isomórficas; ovário séssil, ca. 5,5 mm compr., densamente viloso. Legumes 12-16×6-8 mm, elípticos, compressos, vilosos; sementes oblongas, castanhas a negras.

Materiais selecionados: BRASIL. Minas Gerais: São Roque de Minas, PNSC, estrada para a cachoeira de Rolinhos, 26-IX-1995, fl., Romero et al. 2853 (HRCB, HUFU, VIC); estrada para Fazenda do Fundão, 23-VIII-1997, fl. fr., Romero et al. 4544 (HUFU, VIC); estrada para Sacramento próximo à entrada de São João Batista, 23-VIII-1997, fl., Romero et al. 4536 (HUFU, VIC); Garagem de Pedras, 19-VII-1995, fl., Romero et al. 2659 (HRCB, HUFU, VIC); guarita de Sacramento, 15-IV-1994, fl., Romero et al. 827 (HRCB, HUFU, VIC); 25-VI-1994, fl., Nakajima et al. 359 (HRCB, HUFU, VIC); 19-VII-1994, fl., Nakajima et al. 423 (HRCB, HUFU, VIC); 9-V-1995, fl., Romero et al. 2115 (HRCB, HUFU, VIC); Sede Administrativa, 15-X-1994, fr., Nakajima et al. 511 (HRCB, HUFU, VIC); estrada para a Serra da Chapada, 14-X-1997, fl., Romero et al. 4575 (VIC).

Restrita às Regiões Centro-Oeste e Sudeste do Brasil, ocorre principalmente em formações campestres de cerrado e ao longo de cursos d'água em áreas com 600-1.000 m de altitude (Grear 1970), sendo também citada para campos rupestres da Cadeia do Espinhaço (Gavilanes \& Brandão 1991, Gavilanes et al. 1995). No PNSC, é freqüente em áreas de campo limpo, campo sujo e campo rupestre.

11.3. Eriosema prorepens Benth., Linnaea 22: 524. 1849.

Figura 2m-n

Ervas prostradas. Estípulas elípticas a lanceoladas, 10-15 mm compr., livres, persistentes; estipelas ausentes. Folhas 3-folioladas; pecíolo 4-12 mm compr., viloso; raque 2-10 mm compr., vilosa; folíolos 4-10×1-2 cm, elípticos a oblongos, base aguda, ápice apiculado, densamente vilosos em ambas as faces, face abaxial com glândulas puntiformes amarelas. Inflorescências racemosas, 10-20 cm compr., axilares, 9-12-flora, botão floral reto; cálice 5-laciniado, campanulado, ca. 1,3 cm compr., viloso; corola zigomorfa, amarela, vexilo 1,5-2×1,2 cm, puberulento, alas $14-20 \times 5 \mathrm{~mm}$, pétalas da carena 13-18 $\times 6 \mathrm{~mm}$; androceu diadelfo, 9+1 estames, ca. $16 \mathrm{~mm}$ compr., anteras isomórficas; ovário séssil, ca. $4 \mathrm{~mm}$ compr., viloso. Legumes ca. $2 \times 1 \mathrm{~cm}$, ovados, densamente vilosos; sementes reniformes a ovadas, castanhas a negras.

Materiais examinados: BRASIL. MinAs Gerais: São Roque de Minas, PNSC, cachoeira da Casca D'Anta parte baixa, 29-IX-1995, fl., Nakajima et al. 1410 (HRCB, HUFU, VIC); estrada para Garagem de Pedras, 27-IX-1995, fl. fr., Romero et al. 2887 (HRCB, HUFU, VIC); estrada para Sacramento, entrada para a Garagem de Pedras, 18-X-1994, fl. fr., Romero et al. 1357 (HRCB,HUFU,VIC); 16-X-1997, fl., Romero et al. 4653 (HUFU, VIC); estrada para a Fazenda do Fundão, 23-VIII-1997, fl., Romero et al. 4551 (HUFU, VIC).

Restrita ao Brasil, E. prorepens ocorre em áreas de cerrado de Goiás (Grear 1970), sendo esta a primeira citação da espécie para o Estado de Minas Gerais. No PNSC, a espécie ocorre em campos limpos, campos sujos e em campos rupestres.

12. Erythrina L., Sp. P1. 2: 706-707. 1753.

12.1. Erythrina poeppigiana (Walp.) O.F. Cook, U.S.D.A. Div. Bot. Bull. 25: 57. 1901.

Figura 2o-q

Árvores, ca. $5 \mathrm{~m}$ alt. Estípulas não observadas, caducas; estipelas presentes, glandulares. Folhas 3folioladas; pecíolo 7,5-9 cm compr., glabros; raque 2,7-3,2 cm compr., glabras; folíolos 7-11×4-6,2 cm, elípticos a ovado-elípticos, base obtusa, ápice obtuso, glabrescentes. Inflorescências racemosas, 17-25 cm compr., axilares, ca. 50-flora, botão floral reto; cálice com lobos inconspícuos, campanulado-cilíndrico, ca. $1 \mathrm{~cm}$ compr., seríceo; corola zigomorfa, avermelhada, vexilo ca. $33 \times 12 \mathrm{~mm}$, glabro, alas ca. $7 \times 4 \mathrm{~mm}$, pétalas da carena ca. $30 \times 5 \mathrm{~mm}$; androceu diadelfo, 9+1 estames, ca. $3 \mathrm{~cm}$ compr.; anteras isomórficas; ovário estipitado, ca. $11 \mathrm{~mm}$ compr., viloso. Frutos não observados.

Material examinado: BRASIL. MinAs GERAIS: PNSC, Delfinópolis, estrada da represa dos Peixoto, próximo à cachoeira de Santo Antônio, 23-V-1996 (fl.), Nakajima \& Romero 1766 (HUFU, VIC).

A espécie é citada para o Panamá, Colômbia, Venezuela, Equador, Peru, Brasil e Bolívia (Krukoff \& Barneby 1974). No PNSC, foi coletada em mata ciliar. 
13. Galactia P. Browne, Civ. Nat. Hist. Jamaica 298. 1756.

1. Folhas 1-folioladas 13.5. G. pretiosa var. pretiosa

1. Folhas 3-folioladas

2. Raque foliar ausente; folíolos 0,2-0,3 cm larg.; inflorescência 1-3-flora; corola rósea .... 13.1. G. gracillima

2. Raque foliar 0,3-1,5 cm compr.; folíolos 1,2-5 cm larg.; inflorescência 7-20-flora; corola brancorosada, avermelhada ou violácea

3. Folíolos oblongo-elípticos, face abaxial serícea; corola violácea 13.2. G. heringeri

3. Folíolos ovados a elípticos, face abaxial tomentosa; corola branco rosada ou avermelhada

4. Subarbustos; folíolos de face adaxial serícea; inflorescência 8-20-flora; corola brancorosada 13.3. G. jussiaeana var. jussiaeana

4. Ervas prostradas; folíolos de face adaxial glabra; inflorescência 7-10-flora; corola avermelhada 13.4. G. neesii var. neesii

13.1. Galactia gracillima Benth., Fl. Bras. 15(1B): 142.1862.

Figura 2r

Ervas prostradas. Estípulas lanceoladas, ca. $4 \mathrm{~mm}$ compr., persistentes; estipelas presentes. Folhas 3-folioladas; pecíolo 1-4,5 cm compr., glabrescente; raque ausente; folíolos 3-6×0,2-0,3 cm, lineares, base e ápice agudos, esparsamente vilosos. Inflorescências racemosas, ca. 1,5 cm compr., axilares, 1-3-flora, botão floral reto; cálice 4-laciniado, campanulado, 6-9 mm compr., viloso; corola zigomorfa, rósea, vexilo ca. 10× $6 \mathrm{~mm}$, glabro, alas ca. $8 \times 3 \mathrm{~mm}$, pétalas da carena ca. $6 \times 2 \mathrm{~mm}$; androceu diadelfo, $9+1$ estames, ca. $5 \mathrm{~mm}$ compr., anteras isomórficas; ovário séssil, ca. $2 \mathrm{~mm}$ compr., puberulento. Legumes $2-3 \times 0,4 \mathrm{~cm}$, lineares, vilosos; sementes orbiculares, castanhas.

Material examinado: BRASIL. MinAs Gerais: São Roque de Minas, PNSC, $3 \mathrm{~km}$ da Sede Administrativa, estrada para Sacramento, 10-I-1995, fl. fr., Romero et al. 1687 (HRCB, HUFU, VIC).

Nativa da América do Sul, ocorre na Argentina, Paraguai, Uruguai e Brasil, onde pode ser encontrada na Região Sul e nos estados de São Paulo e Minas Gerais, atingindo altitudes elevadas e ocupando áreas de solos arenosos ou pedregosos (Burkart 1971). No PNSC, foi coletada apenas em uma área de campo limpo.

13.2. Galactia heringeri Burkart, Darwiniana 16(3-4): 772.1971.

Figura 2s

Ervas prostradas. Estípulas lanceoladas, 5-6 mm compr., persistentes; estipelas presentes. Folhas 3-folioladas; pecíolo 5-6,5 mm compr., viloso; raque ca. $3 \mathrm{~mm}$ compr., vilosa; folíolos (3-)4-12,2×
(0,8-)1,2-3 cm, oblongo-elípticos, base obtusa a aguda, ápice obtuso, seríceos. Inflorescências racemosas, 11-22 cm compr., axilares , ca. 20-flora, botão floral reto; cálice 4-laciniado, campanulado, 7-10 mm compr., seríceo; corola zigomorfa, violácea, vexilo 11-19× 7-13 mm, puberulento, alas $12-15 \times 5 \mathrm{~mm}$, pétalas da carena $12-16 \times 4-5 \mathrm{~mm}$; androceu pseudomonadelfo, 10 estames, ca. $12 \mathrm{~mm}$ compr., anteras isomórficas; ovário séssil, ca. $4 \mathrm{~mm}$ compr., seríceo. Frutos não observados.

Materiais examinados: BRASIL. Minas GeraIS: São Roque de Minas, PNSC, Córrego da Fazenda, 20-XI-1995, fl., Romero et al. 3163 (HRCB, HUFU, VIC); Curral de Pedras, 11-I-1995, fl., Romero et al. 1723 (HRCB, HUFU, VIC); 9-I-1998, fl., Romero et al. 4858 (HUFU, VIC); Curral de Pedras, estrada para Sacramento, 11-I-1995, fl., Romero et al. 1716 (HRCB, HUFU,VIC); estrada para a Serra da Chapada, 8-I-1998, fl., Romero et al. 4797 (HUFU, VIC).

Restrita ao Planalto Central do Brasil, ocorre em formações de cerrado e em campos rupestres de Goiás, Minas Gerais e Distrito Federal (Burkart 1971). No PNSC, ocorre em áreas de campo limpo, campo sujo e campo rupestre.

13.3. Galactia jussiaeana Kunth var. jussiaeana, Mimoses 196-200, pl. 55. 1824.

Figura 3a-c

Subarbustos ca. $1 \mathrm{~m}$ alt. Estípulas lanceoladas, 2-8 mm compr., persistentes; estipelas presentes. Folhas 3-folioladas; pecíolo (0,5-)2,5-5 cm compr., tomentoso; raque $3-15 \mathrm{~mm}$ compr., tomentosa; folíolos (1,5-)5,5-11×(1-)2,5-5 cm, ovados a elípticos, base truncada a obtusa, ápice obtuso, emarginado, face 

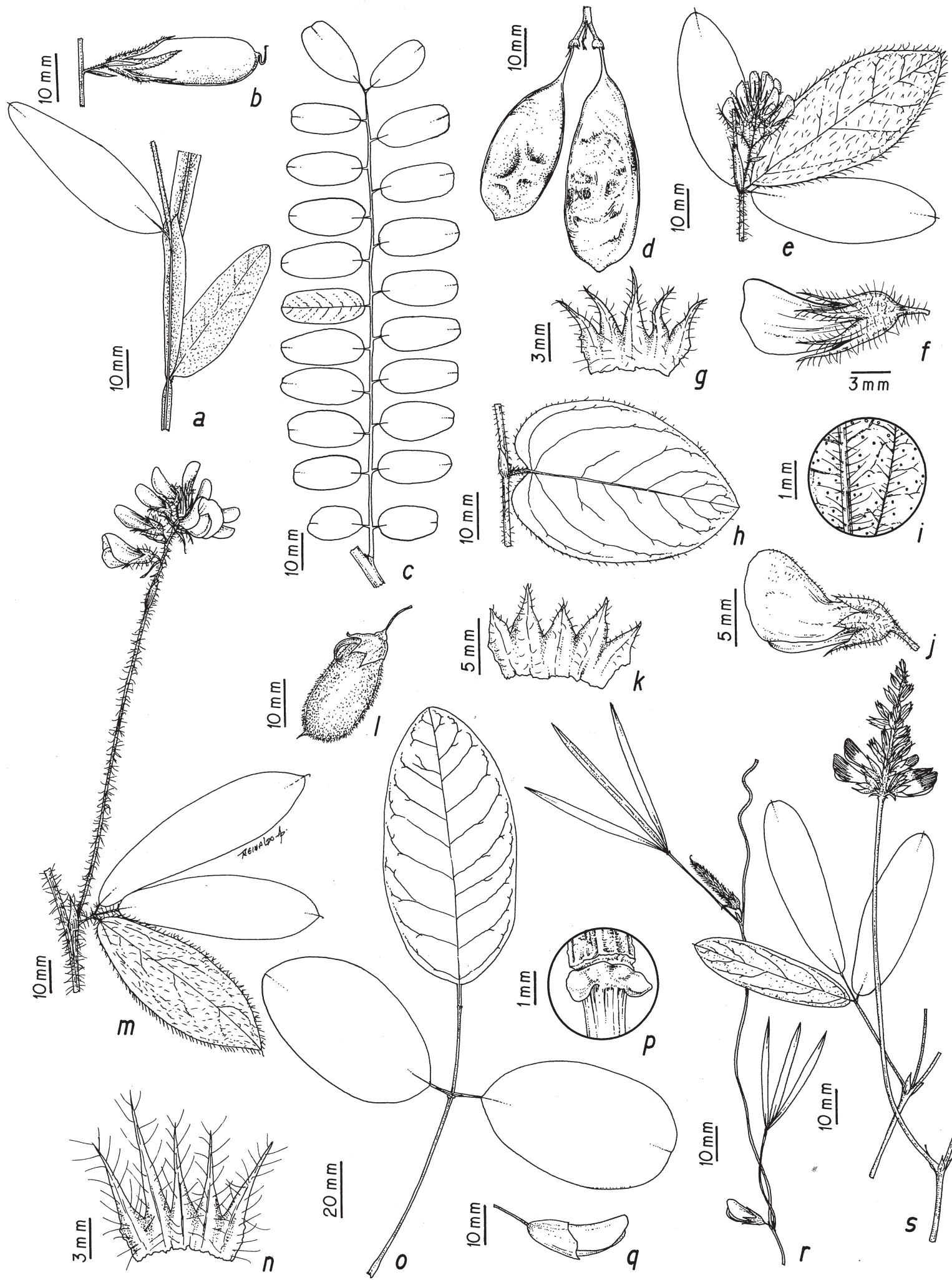

Figura 2. a-b. Crotalaria breviflora. a. Folhas e estípulas. b. Legume (Nakajima et al. 958). c-d. Dalbergia miscolobium. c. Folha. d. Sâmara (Romero et al. 3898). e-g. Eriosema campestre var. campestre. e. Ramo. f. Flor. g. Cálice (Romero et al. 4654). h-1. Eriosema heterophyllum. h. Folha. i. Detalhe das glândulas puntiformes da folha. j. Flor. k. Cálice (Romero et al. 4575). 1. Legume (Romero et al. 4544). m-n. Eriosema prorepens. m. Ramo. n. Cálice (Romero et al. 2887). o-q. Erythrina poeppigiana. o. Folha. p. Detalhe das estipelas glandulares. q. Flor (Nakajima \& Romero 1766). Galactia gracillima. r. Ramo (Romero et al. 1687). Galactia heringeri. s. Ramo (Romero et al. 1716). 
adaxial serícea, face abaxial tomentosa. Inflorescências racemosas, 4,5-14 cm compr., axilares, 8-20flora, botão floral reto; cálice 4-laciniado, campanulado, 15-18 mm compr., seríceo-hirsuto; corola zigomorfa, branco-rosada, vexilo 19-25× $12-15 \mathrm{~mm}$, glabro, alas $15-18 \times 6-7 \mathrm{~mm}$, pétalas da carena 18-21×7-8 mm; androceu diadelfo, 9+1 estames, ca. 1,7 cm compr., anteras isomórficas; ovário séssil, ca. $1 \mathrm{~cm}$ compr., seríceo. Legumes 3-7,5×0,5-1 cm, lineares, seríceos; sementes ovadas, castanhas.

Materiais examinados: BRASIL. MinAS GerAIS: São Roque de Minas, PNSC, Chapadão da Zagaia de frente para a Serra das Sete Voltas, 18-X-1997, fl. fr., Romero et al. 4726 (HUFU, VIC); estrada para a Fazenda do Fundão, 9-XII-1994, fl., Nakajima et al. 749 (HRCB, HUFU, VIC); 22-II-1997, fl., Nakajima et al. 2241 (HUFU, VIC), 19-IV-1997, fl. fr., Romero et al. 4199 (HUFU, VIC); guarita de Sacramento, caminho para o Córrego dos Coelhos, 23-IX-1996, fl. fr., Romero et al. 3633 (HUFU, VIC).

Nativa da América do Sul ocorre, principalmente, em formações campestres submetidas à secas periódicas (Burkart 1971). No PNSC, a variedade foi encontrada em áreas de campo limpo, campo rupestre e campo cerrado.

13.4. Galactia neesii DC. var. neesii, Prodr. 2: 238. 1825.

Figura 3d-f

Ervas prostradas. Estípulas lanceoladas, 4-8 mm compr., persistentes; estipelas presentes. Folhas 3folioladas; pecíolo $(0,5-) 1,5-3,5(-5) \mathrm{cm}$, tomentoso; raque $2-9 \mathrm{~mm}$ compr., tomentosa; folíolos 2,5-7,5(-8,7)×1,2-4,4 cm, ovados a elípticos, base obtusa, ápice obtuso, emarginado, face adaxial glabra, face abaxial tomentosa. Inflorescências racemosas, ca. $15 \mathrm{~cm}$ compr., axilares, 7-10-flora, botão floral reto; cálice 4-laciniado, campanulado, 15-19 mm compr., tomentoso; corola zigomorfa, avermelhada, vexilo 2,3-2,4×1,5-1,6 cm, glabro, alas $22 \times 6-7 \mathrm{~mm}$, pétalas da carena $20 \times 6-7 \mathrm{~mm}$; androceu diadelfo, 9+1 estames, ca. 1,6 cm compr., anteras isomórficas; ovário séssil, ca. $8 \mathrm{~mm}$ compr., tomentoso. Legumes ca. 2,5×0,6 cm, lineares, viloso-tomentosos; sementes ovadas, negras.

Materiais examinados: BRASIL. MinAS GERAIS: São Roque de Minas, PNSC, Serra das Sete Voltas,
19-III-1995, fl. fr., Romero et al. 2023 (HRCB, HUFU, VIC); Torre de Observação, estrada para a divisa do Parque, 17-X-1997, fl., Nakajima et al. 2951 (HUFU, VIC).

Restrita ao Brasil, ocorre em áreas de restinga no Nordeste e em formações campestres do cerrado na Região Sudeste (Burkart 1971). No PNSC, ocorre em áreas de campo rupestre e campo limpo.

\subsection{Galactia pretiosa Burkart var. pretiosa,} Darwiniana 9: 93. 1949.

\section{Figura $3 g$}

Ervas prostradas ou ervas eretas, $30-40 \mathrm{~cm}$ alt. Estípulas linear-lanceoladas, 2-3 mm compr., persistentes; estipelas ausentes. Folhas 1-folioladas; pecíolo 1-6 mm compr., velutino; folíolos (5-) 6,5-12×0,4-1 cm, linear-lanceolados, ou 5,5-9,5× $1,5-4,5 \mathrm{~cm}$, oblongos, base aguda, ápice obtuso, retuso, velutinos. Inflorescências racemosas, 5-9 cm compr., axilares, 3-6-flora, botão floral reto; cálice 4-laciniado, campanulado, 7-12 mm compr., viloso; corola zigomorfa, púrpura, vexilo 11-21×8-17 mm, glabro, alas 16-20×4-6 mm, pétalas da carena 18-21×6-9 mm; androceu diadelfo, 9+1 estames, ca. $13 \mathrm{~mm}$ compr., anteras isomórficas; ovário séssil, ca. $8 \mathrm{~mm}$ compr., hirsuto. Legumes $25-45 \times 4-8 \mathrm{~mm}$, lineares, esparsamente tomentosos; sementes ovadas, castanhas a negras.

Materiais examinados: BRASIL. MinAs Gerais: São Roque de Minas, PNSC, córrego dos coelhos, próximo à guarita de Sacramento 23-IX-1996, fl., Romero et al. 3668 (HUFU, VIC); estrada para Sacramento, 40 km da Sede Administrativa, 18-X-1994, fl. fr., Romero et al. 1368 (HRCB, HUFU, VIC); estrada para São Roque de Minas, próximo à guarita de Sacramento, 18-X-1994, fl. fr., Romero et al. 1379 (HRCB, HUFU, VIC); 17-X-1997, fl., Nakajima et al. 2888 (HUFU, VIC); guarita de Sacramento, 24-IX-1995, fl., Romero et al. 2756 (HRCB, HUFU, VIC); 19-VIII-1994, fl., Nakajima et al. 398 (HRCB, HUFU, VIC); 14-X-1994, fl. fr., Romero et al. 1192 (HRCB, HUFU, VIC).

Distribui-se ao sul da América do Sul e no Brasil é citada para a Bahia, Minas Gerais, São Paulo, Paraná, Santa Catarina e Rio Grande do Sul, ocupando, geralmente, áreas de altitudes elevadas e solos pedregosos (Burkart 1971). No PNSC, a variedade foi encontrada em áreas de campo limpo, campo sujo e cerrado. 
14. Lupinus L., Sp. P1. 2: 721-722. 1753.

1. Folhas sésseis; folíolos 0,5-5 mm larg., lineares ou lanceolados; vexilo ca. $15 \mathrm{~mm}$ compr.; ovário barbado 14.1. L. coriaceus

1. Folhas pecioladas, pecíolo ca. $4 \mathrm{~mm}$ compr.; folíolos 11-31 mm larg., elípticos ou elíptico-lanceolados; vexilo 17-20 mm compr.; ovário velutino 14.2. L. subsessilis

14.1. Lupinus coriaceus Benth., Ann. Nat. Hist. 3: 430. 1839.

Figura $3 \mathrm{~h}-\mathrm{j}$

Subarbustos, ca. $30 \mathrm{~cm}$ alt. Estípulas ausentes; estipelas ausentes. Folhas 1-folioladas; sésseis; folíolos 22-62 $\times 0,5-5 \mathrm{~mm}$, lineares, lanceolados, base aguda e ápice agudo, seríceos. Inflorescências racemosas, 7,5-13,5 cm compr., terminais, 13-20-flora; cálice 5-laciniado, bilabiado, 8-10 mm compr., seríceo; corola zigomorfa, roxo-azulada, vexilo ca. $15 \times 12 \mathrm{~mm}$, glabro, alas 14-16×6-8 mm, pétalas da carena 13-14×3-4 mm; androceu monadelfo, 10 estames, ca. 1,2 cm compr., anteras dimórficas: 5 longas e basifixas alternadas com 5 menores e dorsifixas; ovário séssil, ca. $6 \mathrm{~mm}$ compr., barbado. Legumes 4-6,5×1 cm, planos, glabrescentes; sementes suborbiculares, compressas, amareladas.

Materiais examinados: BRASIL. MinAs Gerais: São Roque de Minas, PNSC, estrada para Sacramento, após entrada para a cachoeira da Casca D'Anta, 12-I-1995, fr., Romero et al. 1753 (HRCB, HUFU, VIC); morro após a nascente do Rio São Francisco, 20-XI-1996, fl., Romero et al. 3776; 3779; 3780 (HUFU, VIC).

Ocorre na Cadeia do Espinhaço, em Minas Gerais (Monteiro \& Gibbs 1986, Giulietti et al. 1987, Brandão et al. 1995), sendo considerada ameaçada de extinção devido à sua distribuição restrita a pequenas populações, segundo os critérios da IUCN (Mendonça $\&$ Lins 2000). No PNSC, a espécie ocorre apenas nos campos rupestres.

14.2. Lupinus subsessilis Benth., Ann. Nat. Hist. 3: 430. 1839.

Figura 3k

Subarbustos, ca. $30 \mathrm{~cm}$ alt. Estípulas lanceoladas, ca. $3 \mathrm{~mm}$ compr., conatas, persistentes; estipelas ausentes. Folhas 1-folioladas; pecíolo ca. $4 \mathrm{~mm}$ compr., seríceo; folíolos 4,8-7,5(-9,8)×1,1-3,1 cm, elípticos, elíptico-lanceolados, base aguda, ápice agudo a obtuso, seríceos. Inflorescências racemosas, 12,5-20 cm compr., terminais, 16-18-flora, botão floral reto; cálice 5-laciniado, campanulado, ca. $12 \mathrm{~mm}$ compr., viloso; corola zigomorfa, roxo-azulada, vexilo $17-20 \times 9-18 \mathrm{~mm}$, glabro, alas 17-19×7-9 $\mathrm{mm}$, pétalas da carena $15-18 \times 5 \mathrm{~mm}$; androceu monadelfo, 10 estames, ca. $15 \mathrm{~mm}$ compr., anteras dimórficas: 5 longas e basifixas alternadas com 5 menores e dorsifixas; ovário séssil, ca. $6 \mathrm{~mm}$ compr., velutino. Frutos não observados.

Materiais examinados: BRASIL. MinAs Gerais: São Roque de Minas, PNSC, vale da nascente do Rio São Francisco, 7-XII-1994, fl., Nakajima et al. 688 (HRCB, HUFU, VIC); 20-XI-1996, fl., Romero et al. 3764 (HUFU, VIC).

Até o momento era citada apenas para o estado de Goiás (Monteiro \& Gibbs 1986), sua distribuição está sendo ampliada para Minas Gerais neste trabalho. No PNSC, a espécie apresentou ocorrência restrita a uma área de campo limpo.

15. Machaerium Pers., Syn. P1. 2: 276. 1807.

15.1. Machaerium villosum Vogel, Linnaea 11: 189. 1837.

Figura 31-m

Árvores, 6-15 m alt. Estípulas precocemente caducas; estipelas ausentes. Folhas imparipinadas, 17-25-folioladas, pecíolo 2,5-7,4 cm compr., viloso a glabrescente; raque ca. $20 \mathrm{~cm}$ compr., vilosa a glabrescente; folíolos (4,5-)5,5-7,8×(1-)1,5-2(-2,7) cm, oblongos, base obtusa, ápice agudo, face adaxial esparsamente vilosa, face abaxial densamente vilosa. Inflorescências paniculadas, 7,5-9,1 cm compr., axilares, pluri-flora, botão floral reto; cálice 5-laciniado, campanulado, ca. $5 \mathrm{~mm}$ compr., seríceo; corola zigomorfa, roxa, vexilo ca. $9 \mathrm{~mm}$ compr., seríceo, alas ca. $7 \mathrm{~mm}$ compr., pétalas da carena ca. $8 \mathrm{~mm}$ compr.; androceu monadelfo, 10 estames, 6-7 mm compr., anteras isomórficas; ovário estipitado, ca. $3 \mathrm{~mm}$ compr., viloso. Sâmaras 5-7,5×1,6-2 cm, oblongas, puberulentas, região seminífera proximal; sementes reniformes, castanhas.

Materiais examinados: BRASIL. MinAs GerAIS: São Roque de Minas, PNSC, cachoeira da Casca D'Anta parte baixa, 19-X-1994, fl., Nakajima et al. 580 (HRCB, HUFU, VIC); 21-II-1997, fr., Romero et al. 3945 (HUFU, VIC); mata próxima à cachoeira dos 
Rolinhos, 23-II-1997, fr., Romero et al. 4018 (HUFU, VIC).

Material adicional examinado: BRASIL. Minas Gerais: Ouro Preto, Parque Estadual do Itacolomi, trilha da Alcan, 24-X-2004, fl., Lima \& Garcia 227 (VIC).

Ocorre em Minas Gerais (Bentham 1862) e São Paulo, ocupando áreas de mata, cerrado sensu stricto e cerradão (Sartori \& Tozzi 1998). No PNSC, ocorre apenas em áreas de mata.

16. Periandra Mart. ex Benth., Comm. Legum. Gen. 56. 1837.

1. Raque foliar e pecíolo esparsamente tomentosos; inflorescência congesta, 3$6,5 \mathrm{~cm}$ compr., pluriflora .... 16.2. P. mediterranea

1. Raque foliar e pecíolo glabrescentes; inflorescência laxa, ca. $8 \mathrm{~cm}$ compr., 2-8-flora 16.1. P. gracilis

16.1. Periandra gracilis H. S. Irwin \& Arroyo, Brittonia 24(3): 327-329. 1972.

Figura 3n

Arbustos, ca.1,5 m alt. Estípulas lanceoladas, 2-5 $\mathrm{mm}$ compr., persistentes; estipelas presentes. Folhas 3-folioladas; pecíolo 2-12 mm compr., glabrescente; raque 5-17 $\mathrm{mm}$ compr., glabrescente; folíolos 4,2-8,2×0,6-1,2 cm, oblongo-lanceolados, base obtusa a aguda, ápice obtuso a agudo, face adaxial glabra, face abaxial tomentosa. Inflorescências racemosas, laxas, ca. $8 \mathrm{~cm}$ compr., axilares, terminais, 2-8-flora, botão floral reto; cálice 5-laciniado, campanulado, ca. 3,5 mm compr., puberulento; corola zigomorfa, púrpura, ressupinada, vexilo $22-26 \times 22-29 \mathrm{~mm}$, puberulento, alas 21-23 $\times 18 \mathrm{~mm}$, pétalas da carena ca. $22 \times 12 \mathrm{~mm}$; androceu diadelfo, $9+1$ estames, 17-23 mm compr., anteras isomórficas; ovário subséssil, ca. $14 \mathrm{~mm}$ compr., seríceo. Frutos não observados.

Materiais examinados: BRASIL. MinAs Gerais: São Roque de Minas, PNSC, cachoeira da Casca D'Anta parte baixa, 21-II-1997, fl., Romero et al. 3942 (HUFU, VIC); cachoeira dos Rolinhos, "ilhota", 23-II-1997, fl., Romero et al. 3981 (HUFU, VIC).

Citada anteriormente para Goiás, Brasília e Mato Grosso do Sul (Funch \& Barroso 1999), esta é a primeira ocorrência da espécie relatada para Minas Gerais. Ocorre no cerrado, geralmente, associada a cursos d'água (Funch \& Barroso 1999) e, no PNSC, apresentou ocorrência restrita às áreas de mata ciliar.
16.2. Periandra mediterranea (Vell.) Taub., in Engl. \& Prantl. Nat. Pflanzenfam. 3(3): 359. 1894. Figura 30

Arbustos, ca. 1,5 m alt. ou subarbustos prostrados. Estípulas ovado-lanceoladas, 2-4 mm compr., persistentes; estipelas presentes. Folhas 3-folioladas; pecíolo 2-4 mm compr., esparsamente tomentoso; raque 3-5 mm compr., esparsamente tomentosa; folíolos (2-)3-7(-8,2)×(0,5-)1-2(-3,5) cm, elípticos, obovados, oblongo-lanceolados, base aguda, ápice obtuso, retuso ou agudo, face adaxial glabra, face abaxial tomentosa. Inflorescências racemosas, congestas, 3-6,5 cm compr., axilares, terminais, pluri-flora, botão floral reto; cálice 5-laciniado, campanulado, 6-8 mm compr., puberulento; corola zigomorfa, violácea, ressupinada, vexilo (15-)22-30×(12-)20-30 mm, puberulento, alas 21-30×10-14 mm, pétalas da carena 22-28 $\times 10-13 \mathrm{~mm}$; androceu diadelfo, 9+1 estames, ca. $25 \mathrm{~mm}$ compr., anteras isomórficas; ovário subséssil, 10-15 mm compr., viloso. Legumes (3,4-)7-12×0,6-1 cm, lineares, planos, puberulentos a glabrescentes; sementes orbiculares, compressas, castanho-avermelhadas.

Materiais selecionados: BRASIL. MinAS GERAIS: São Roque de Minas, PNSC, cachoeira da Casca D'Anta, 20-IV-1994, fl., Romero et al. 956 (HRCB, HUFU, VIC); cachoeira de Rolinhos parte alta, 23-VIII-1997, fl., Romero et al. 4509 (HRCB, HUFU, VIC); cachoeira de Rolinhos parte baixa, 29-VI-1997, fl., Romero et al. 4360 (HUFU, VIC); Centro de Visitantes, 25-IX-1995, fl., Nakajima et al. 1293 (HRCB, HUFU, VIC); estrada para São Roque de Minas próximo à guarita de Sacramento, 18-X-1994, fl. fr., Romero et al. 1382 (HRCB, HUFU, VIC); guarita 1 , 23-II-1994, fl., Nakajima et al. 179 (HRCB, HUFU, VIC); guarita de Sacramento, 16-III-1995, fl., Romero et al. 1876 (HRCB, HUFU, VIC); Sede Administrativa, 15-VII-1995, fl., Romero et al. 2382 (HRCB, HUFU, VIC); 19-XI-1995, fl., Nakajima et al. 1456 (HRCB, HUFU, VIC); 10-I-1995, fl. fr., Romero et al. 1662 (HRCB, HUFU, VIC).

Ocorre na maioria dos estados brasileiros, estendendo-se pelos cerrados, caatingas e campos de restinga (Funch \& Barroso 1999), sendo característica dos campos rupestres da Cadeia do Espinhaço (Harley \& Simmons 1986, Giulietti et al. 1987, Brandão \& Silva Filho 1993, Pirani et al. 1994, Brandão et al. 1995, Gavilanes et al. 1995, Lewis 1995, Zappi et al. 2003, Dutra 2005). No PNSC, apresenta ampla 
ocorrência e foi coletada para diversas fitofisionomias campestres.

17. Platycyamus Benth., Fl. Bras. 15(1): 323. 1862.

\subsection{Platycyamus regnellii Benth., Fl. Bras.15(1):} 323. 1862.

Figura $3 p$

Árvores, ca.15 m alt. Estípulas lanceoladas, ca. $2 \mathrm{~mm}$ compr., persistentes; estipelas presentes, não glandulares. Folhas 3-folioladas; pecíolo 4,5-12,5 cm compr., tomentoso; raque 2,5-6 cm compr., tomentosa; folíolos 9,4-13,5×6-11,5 cm, ovado-romboidais, base truncada a atenuada, ápice agudo, tomentosos. Inflorescências paniculadas, 20-40 cm compr., axilares, terminais, ca. 100-flora, botão floral reto; cálice 5-laciniado, campanulado, ca. $12 \mathrm{~mm}$ compr., internamente velutino, externamente seríceo; corola zigomorfa, lilás a púrpura, vexilo 12-18×12-15 mm, glabro, alas 17-18×4-5 mm, pétalas da carena $17-19 \times 4 \mathrm{~mm}$; androceu diadelfo, 9+1 estames, ca. $17 \mathrm{~mm}$ compr., anteras isomórficas; ovário séssil, ca. $8 \mathrm{~mm}$ compr., viloso. Legumes 15,5-21,5 cm, oblongos, ferrugíneotomentosos; sementes não observadas.

Material examinado: BRASIL. Minas Gerais: São Roque de Minas, PNSC, cachoeira da Casca D'Anta, próximo à guarita 3, 21-III-1995, fl., Romero et al. 2064 (HRCB, HUFU, VIC).

Material adicional examinado: BRASIL. MinAS GERAIS: Marliéria, Parque Estadual do Rio Doce, trilha da Lagoa do Meio, VI-1998, fr., Bortoluzzi et al. 177 (VIC).

Ocorre em formações florestais de Goiás, sul da Bahia, Espírito Santo, São Paulo (Lorenzi 2002) e Minas Gerais (Bortoluzzi et al. 2004). No PNSC, a espécie foi coletada apenas em uma área de mata.

18. Platypodium Vogel, Linnaea 11: 420. 1837.

18.1. Platypodium elegans Vogel, Linnaea 11: 420-422. 1837.

Árvores ca. $5 \mathrm{~m}$ alt. Estípulas lineares, 4-5 mm compr., caducas; estipelas ausentes. Folhas imparipinadas, 13-17-folioladas; pecíolo 1-1,7 cm compr., tomentoso; raque $8-12 \mathrm{~cm}$ compr., tomentosa; folíolos 2-3,5×0,8-1,4 cm, oblongos, base oblíqua à obtusa, ápice emarginado, face adaxial glabra, face abaxial tomentosa. Inflorescências racemosas, ca. 12 cm compr., axilares, ca. 15-flora, botão floral reto; cálice 5-laciniado, campanulado, 12-15 mm compr., internamente seríceo, externamente glabro; corola zigomorfa, amarela, vexilo $15-17 \times 20 \mathrm{~mm}$, glabro, alas 17-21 mm compr., pétalas da carena 14-17 mm compr.; androceu poliadelfo, $4+1+4+1$ estames, ca. $12 \mathrm{~mm}$ compr.; anteras isomórficas; ovário estipitado, ca. 4 mm compr., glabro. Sâmaras 8-8,9x2-2,2 cm compr., oblongas, glabrescentes, região seminífera distal; sementes oblongas, castanhas.

Material examinado: BRASIL. MinAs GeraIs: São Roque de Minas, PNSC, estrada guarita da Casca D’Anta, 19-X-1994, fl., Nakajima et al. 623 (HRCB, HUFU, VIC).

Material adicional examinado: BRASIL. MinAs GeRAIS: Montes Claros, Centro de Agricultura Alternativa, 25V-1994, fr., Sevilha 25 (VIC).

Ocorre nas Américas Central e do Sul (ILDIS 2005), sendo que no Brasil ocupa, principalmente, áreas de cerrado (Mendonça et al. 1998; Filardi 2005), além de áreas de caatinga (Lewis 1987) e de mata atlântica (Bortoluzzi et al. 2004). No PNSC, apresentou ocorrência restrita a uma área de mata.

19. Poiretia Vent., Mem. Cl. Sci. Math. Inst. Natl. France 8: 4-6. 1807.

19.1. Poiretia angustifolia Vogel, Linnaea 12: 53. 1838.

Figura $4 \mathrm{a}$

Subarbustos, ca. $50 \mathrm{~cm}$ alt.. Estípulas lineares, 2-6 mm compr., persistentes, não prolongadas abaixo do ponto de inserção; estipelas presentes. Folhas paripinadas, 4-folioladas; pecíolo 8-15 mm compr., com glândulas puntiformes; raque 4-8 mm compr., com glândulas puntiformes; folíolos 13-25×1-4 mm, lineares a oblongo-lineares, base aguda, ápice agudo, face adaxial glabra, face abaxial com glândulas puntiformes. Inflorescências racemosas, 6-8 mm compr., axilares, 2-4-flora, botão floral reto; cálice 5-laciniado, campanulado, 1,5-2 mm compr., com glândulas puntiformes; corola zigomorfa, amarela, com glândulas puntiformes, vexilo 6-7×6-8 mm, alas ca. $6 \times 2 \mathrm{~mm}$, pétalas da carena ca. $6 \times 2 \mathrm{~mm}$; androceu monadelfo, 10 estames, ca. $6 \mathrm{~mm}$ compr., anteras dimórficas: 5 longas e basifixas alternadas com 5 menores e dorsifixas; ovário séssil, ca. 4 mm compr., com glândulas puntiformes. Legumes $25 \times 4-5 \mathrm{~mm}$, lineares, glabros; sementes não observadas.

Materiais examinados: BRASIL. MinAs GeRAIS: São Roque de Minas, PNSC, estrada para a cachoeira de 


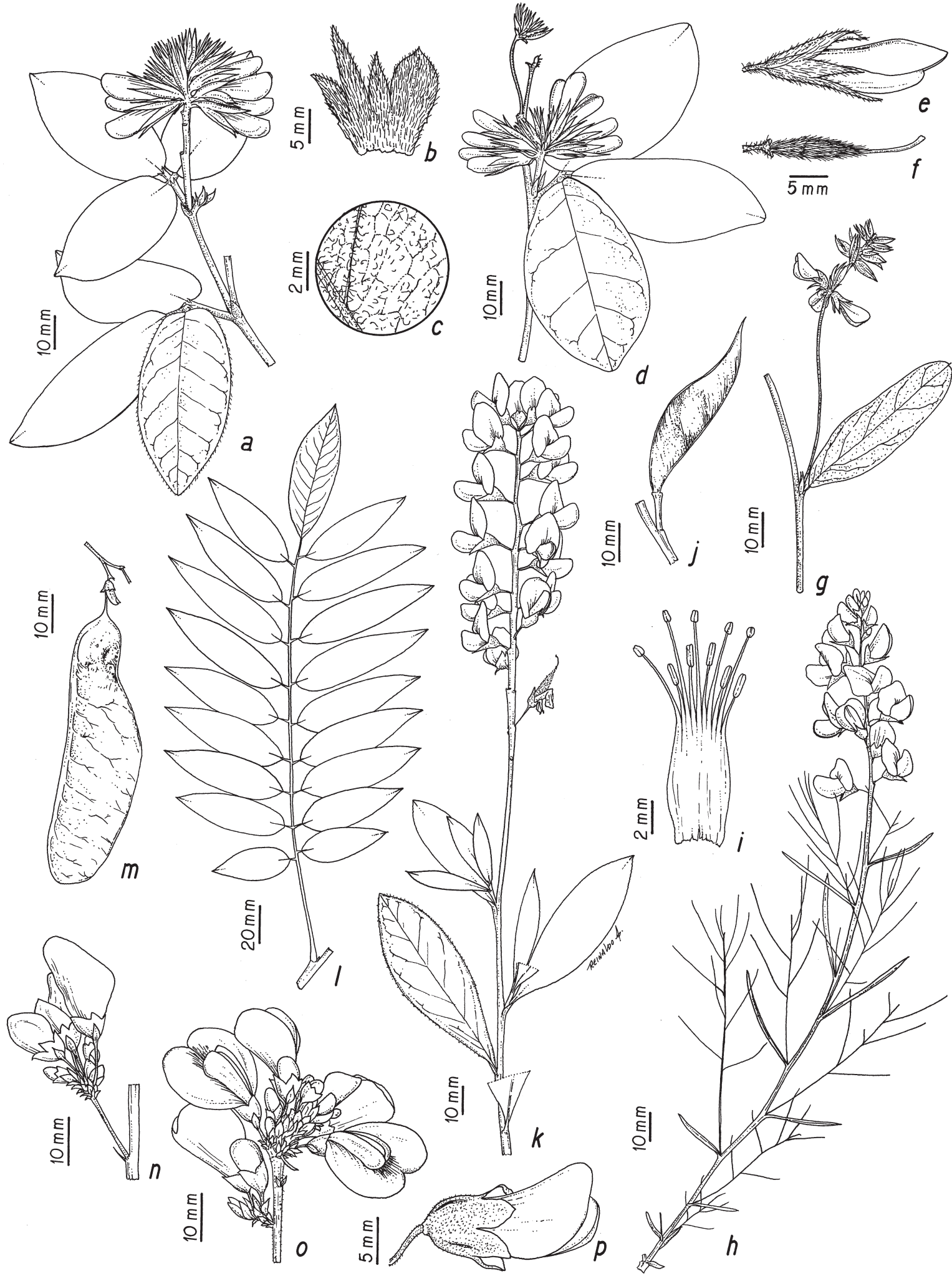

Figura 3. a-c. Galactia jussiaeana var. jussiaeana. a. Ramo. b. Cálice. c. Detalhe do indumento da face adaxial do folíolo (Romero et al. 4726). d-f. Galactia neesii var. neesii. d. Ramo. e. Flor. f. Gineceu (Romero et al. 2023). Galactia pretiosa var. pretiosa. g. Ramo (Nakajima et al. 398). h-j. Lupinus coriaceus. h. Ramo. i. Androceu (Romero \& Nakajima 3776). j. Legume (Romero et al. 1753). Lupinus subsessilis. k. Ramo (Nakajima \& Romero 688). 1-m. Machaerium villosum. 1. Folha (Nakajima et al. 580). m. Sâmara (Romero et al. 3945). Periandra gracilis. n. Inflorescência (Romero et al. 3942). Periandra mediterranea. o. Inflorescência (Romero et al. 4509). Platycyamus regnellii. p. Flor (Romero et al. 2064). 
Rolinhos, 9-I-1998, fl., Romero et al. 4869 (HUFU, VIC); estrada para Sacramento, $2 \mathrm{~km}$ após a entrada para a Fazenda do Fundão, 13-I-1995, fl., Romero et al. 1787 (HRCB, HUFU, VIC); torre de observação, estrada Sacramento-São Roque de Minas, 11-I-1998, fl., Romero et al. 4998 (HUFU, VIC).

Ocorre nos estados de Goiás, Minas Gerais, Rio de Janeiro, São Paulo e Paraná (Müller 1984), onde habita formações campestres áridas (Bentham 1862). No PNSC, foi coletada em áreas de campo limpo e de campo sujo.

20. Stylosanthes Sw., Prodr. 7, 108. 1788.

1. Estípulas 4-8 mm compr.; pecíolo puberulento; lomento $0,5 \times 1,5 \mathrm{~mm}$

20.2. S. guianensis

1. Estípulas ca. $10 \mathrm{~mm}$ compr.; pecíolo tomentoso com tricomas glandulares; lomento $1,5-2,5 \times 2-2,3 \mathrm{~mm}$ 20.1. S. gracilis

20.1. Stylosanthes gracilis Kunth, Nov. Gen. Sp. 6: 507-508. 1823.

Figura $4 b$

Ervas eretas, $20-30 \mathrm{~cm}$ alt. Estípulas amplexicaules, 2-dentadas, ca. $1 \mathrm{~cm}$ compr., persistentes; estipelas ausentes. Folhas 3-folioladas; pecíolo ca. $1 \mathrm{~cm}$ compr., tomentoso, com tricomas glandulares; raque ausente; folíolos (3-)4-9(-14)× 2-10 mm, oblongo-elípticos, base aguda, ápice agudo, face adaxial glabra, face abaxial esparsamente serícea a glabrescente. Inflorescências espiciformes, ca. $1 \mathrm{~cm}$ compr., terminais ou axilares, pluri-flora; cálice 4-laciniado, tubuloso, ca. $7 \mathrm{~mm}$ compr., glabro; corola zigomorfa, amarela, vexilo ca. $5 \times 3 \mathrm{~mm}$, glabro, alas $3-5 \times 1 \mathrm{~mm}$, pétalas da carena ca. $2 \times 1 \mathrm{~mm}$; androceu monadelfo, 10 estames, ca. $4 \mathrm{~mm}$ compr., anteras dimórficas: 5 longas e basifixas alternadas com 5 menores e dorsifixas; ovário séssil, ca. $3 \mathrm{~mm}$ compr., glabro. Lomentos, 1-articulado, 1,5-2,5×2-2,3 mm compr., glabros; sementes ovóides, negras.

Materiais examinados: BRASIL. MinAs GeraIs: São Roque de Minas, PNSC, Curral de Pedras, 18-IV-1994, fl. fr., Romero et al. 927 (HRCB, HUFU, VIC); Retiro das Pedras, próximo à divisa do Parque, 23-II-1997, fl. fr., Romero et al. 3969 (HUFU, VIC); Sede Administrativa, 10-I-1995, fl., Romero et al. 1664 (HRCB,HUFU,VIC); Torre de Observação, 13-I-1995, fl., Romero et al. 1795 (HRCB, HUFU, VIC).
Ocorre na América Central e América do Sul, distribuindo-se do Panamá ao Paraguai (Mohlenbrock 1957). No Brasil, a espécie é relatada para as regiões Norte, Nordeste, Centro-Oeste e Sudeste (Ferreira $\&$ Costa 1979). No PNSC, a espécie ocorre em áreas de campo limpo e campo rupestre.

20.2. Stylosanthes guianensis (Aubl.) Sw., Kongl.

Vetensk. Acad. Nya Handl. 10: 301-302. 1789.

Figura 4c-d

Subarbustos prostrados. Estípulas amplexicaules, 2-dentadas, 4-8 mm compr., persistentes; estipelas ausentes. Folhas 3-folioladas; pecíolo 2-10 mm compr., puberulento; raque ausente; folíolos (3-)4-9(-14)× 2-10 mm, oblongo-elípticos, base aguda, ápice agudo, pulverulentos. Inflorescências espiciformes, 5-15 mm compr., axilares, multi-flora, botão floral reto; cálice 4-laciniado, tubuloso, ca. $7 \mathrm{~mm}$ compr., glabrescente; corola zigomorfa, amarela, vexilo ca. $5 \times 3 \mathrm{~mm}$, glabro, alas 3-5×1 mm, pétalas da carena ca. $2 \times 1 \mathrm{~mm}$; androceu monadelfo, 10 estames, ca. $5 \mathrm{~mm}$ compr., anteras dimórficas: 5 longas e basifixas alternadas com 5 menores e dorsifixas; ovário séssil, ca. $3 \mathrm{~mm}$ compr., glabro. Lomentos, 1-articulado, ca. $0,5 \times 1,5 \mathrm{~mm}$, orbiculares, glabrescentes, estilete residual menor $1 \mathrm{~mm}$ compr.; sementes ovóides, negras, marrons ou amarelas.

Material examinado: BRASIL. Minas Gerais: São Roque de Minas, PNSC, cachoeira de Rolinhos, 14-V-1995, fl. fr., Romero et al. 2300 (HRCB, HUFU, VIC).

Apresenta-se amplamente distribuída em todo continente americano (Mohlenbrock 1963). No Brasil, ocorre nos estados do Pará, Maranhão, Pernambuco, Paraíba, Ceará, Bahia, Goiás, Mato Grosso, Minas Gerais, Rio de Janeiro, São Paulo e Paraná, ocupando diversos tipos de formações campestres (Ferreira \& Costa 1979), inclusive campos rupestres da Cadeia do Espinhaço (Harley \& Simmons 1986, Giulietti et al. 1987, Gavilanes \& Brandão 1991, Brandão \& Silva Filho 1993, Pirani et al. 1994, Lewis 1995, Munhoz \& Proença 1998, Zappi et al. 2003). No PNSC, a espécie ocorre em áreas de campo limpo e campo rupestre.

21. Swartzia Schreb., Gen. P1. 2: 518. 1791.

21.1. Swartzia apetala Raddi var. apetala, Mem. Mat. Fis. Soc. Ital. Sci. Modena, Pt. Mem. Fis. 18(2): 398. 1820.

Figura $4 \mathrm{e}-\mathrm{f}$ 
Árvores, ca. $5 \mathrm{~m}$ alt. Estípulas lanceoladas, ca. $4 \mathrm{~mm}$ compr., persistentes; estipelas presentes. Folhas imparipinadas, 7-9-folioladas; pecíolo 5-15 mm compr., puberulento a glabrescente, raque $3-15 \mathrm{~cm}$ compr., marginada, glabrescente; folíolos (15-)30-76× (7-)12-24 mm, elípticos ou ovados, base cuneada, ápice acuminado a obtuso, puberulentos a glabrescentes. Flores não observadas. Legumes (1,2-)1,8-3× (0,6-)1-2,5 cm, ovóides a globosos, glabros, monospérmicos; sementes globosas, negras, arilo branco.

Material examinado: BRASIL. MinAs GeraIs: São Roque de Minas, PNSC, cachoeira da Casca D'Anta parte baixa, 19-X-1994, fr., Nakajima et al. 590 (HRCB, HUFU, VIC).

Amplamente distribuída no leste de Minas Gerais, Rio de Janeiro e Espírito Santo, principalmente em áreas litorâneas, sendo também citada para Alagoas e Bahia (Mansano \& Tozzi 1999). No PNSC, foi coletada apenas em uma área no interior de mata.

22. Vigna Savi, Nuovo Giorn. Lett. 8: 113. 1824.

1. Pecíolo 3-4 mm compr.; corola esverdeada ................................. 22.2. V. firmula

1. Pecíolo 12-65 mm compr.; corola violácea ou lilás

2. Estípulas lanceoladas, pecíolo glabrescente; corola lilás .. 22.3. V. peduncularis

2. Estípulas triangulares, pecíolo tomentoso; corola violácea ..... 22.1. V. candida

22.1. Vigna candida (Vell.) Maréchal, Mascherpa \& Stainier, Taxon 27 (2-3): 201. 1978.

Figura $4 \mathrm{~g}$

Trepadeiras. Estípulas triangulares, ca. $3 \mathrm{~mm}$ compr., persistentes; estipelas presentes. Folhas 3folioladas; pecíolo 1,2-6,5 cm compr., tomentoso; raque 0,3-1,5 cm compr., tomentosa; folíolos (3-)5-11× (1,2-)2,2-8,2cm, ovado-triangulares, assimétricos, base cordada a truncada, ápice agudo, glabros a esparsamente puberulentos em ambas as faces. Inflorescências racemosas, nodosas, 10-20 cm compr., axilares, 5-9-flora, botão floral curvo; cálice 5-laciniado, campanulado, 7-10 mm compr., esparsamente seríceo; corola zigomorfa, violácea, não ressupinada, vexilo $2-2,4 \times 2,2 \mathrm{~cm}$, glabro, alas $2,5-3 \times 1-1,5 \mathrm{~cm}$, pétalas da carena 1,5-2×0,7-1 cm; androceu diadelfo, 9+1 estames, 2,8-3 cm compr., anteras isomórficas; ovário estipitado, 5-6 mm compr., esparsamente puberulento. Legumes ca. $5 \times 0,3 \mathrm{~cm}$, lineares, glabros; sementes oblongas, castanhas.

Materiais examinados: BRASIL. MinAS GERAIS: São Roque de Minas, PNSC, Chapadão do Diamante, 16-I-1995, fl., Romero et al. 2469 (HRCB, HUFU, VIC); guarita de Sacramento, 20-IX-1996, fl. fr., Romero et al. 3544 (HUFU, VIC).

Nativa da América do Sul (Bentham 1862) é citada, no Brasil, para os estados da Bahia (Lewis 1987), Goiás e Minas Gerais (Mendonça et al. 1998). No PNSC, a espécie foi coletada em áreas de mata.

22.2. Vigna firmula (Mart. ex Benth.) Maréchal, Mascherpa \& Stainier, Taxon 27 (2-3): 201. 1978. Figura $4 \mathrm{~h}$

Trepadeiras. Estípulas triangulares, 3-4 mm compr., persistentes; estipelas presentes. Folhas 3-folioladas; pecíolo 3-4 mm compr., glabrescente; raque 1,2-2 cm compr., glabrescente; folíolos 4,4-7,2×2,6-5,1 cm, elípticos a obovados, base cordada, ápice obcordado, face adaxial glabra, face abaxial tomentosa. Inflorescências racemosas, nodosas, 5,5-7,5 cm compr., axilares, 5-flora; botão floral curvo; cálice 5-laciniado, campanulado, ca. $4 \mathrm{~mm}$ compr., glabrescente; corola zigomorfa, esverdeada, não ressupinada, vexilo ca. 1,5×1,3 cm, glabro, alas 1,4-1,5×0,3 cm, pétalas da carena ca. $3 \times 0,2 \mathrm{~cm}$; androceu diadelfo, 9+1 estames, ca. $3 \mathrm{~cm}$ compr., anteras isomórficas; ovário subséssil, ca. $6 \mathrm{~mm}$ compr., tomentoso. Frutos não observados.

Material examinado: BRASIL. Minas Gerais: São Roque de Minas, PNSC, estrada para a Fazenda do Fundão, 25-VI-1997, fl., Romero et al. 4260 (HUFU, VIC).

Ocorre no Paraguai e Brasil (Maréchal et al. 1978), onde é citada para campos rupestres da Cadeia do Espinhaço (Giulietti et al. 1987, Lewis 1995, Zappi et al. 2003). No PNSC, habita áreas de campo rupestre.

22.3. Vigna peduncularis (Kunth) Fawc. \& Rendle, F1. Jamaica 4(2): 68. 1920.

Figura 4i

Trepadeiras. Estípulas lanceoladas, 3-4 mm compr., persistentes; estipelas presentes. Folhas 3-folioladas; pecíolo 1,8-5,6 cm, glabrescente; raque 5-11 mm compr., glabrescente; folíolos 2,5-5× 0,6-2,4 cm, oblongos a obovados, base obtusa, ápice 
agudo, glabrescentes. Inflorescências racemosas, nodosas, 3,5-22,5 cm compr., axilares, 3-6-flora; botão floral curvo; cálice 5-laciniado, campanulado, ca. $4 \mathrm{~mm}$ compr., glabro; corola zigomorfa, violácea, não ressupinada, vexilo $1,8-1,9 \times 0,8-1,3 \mathrm{~cm}$, glabro; alas $1,8-1,9 \times 1 \mathrm{~cm}$, pétalas da carena $1,9-2 \times 1 \mathrm{~cm}$., torcidas lateralmente; androceu diadelfo, 9+1 estames, 2,1-2,4 cm compr., anteras isomórficas; ovário estipitado, ca. $8 \mathrm{~mm}$ compr., tomentoso. Legumes ca. $54 \times 4 \mathrm{~mm}$, lineares, glabrescentes; sementes oblongas, castanhas com manchas negras.

Materiais examinados: BRASIL. MinAs Gerais: São Roque de Minas, PNSC, estrada para a Fazenda do Fundão, 22-II-1997, fl., Nakajima et al. 2244 (HUFU, VIC); 22-II-1997, fl. fr., Romero et al. 4193 (HUFU, VIC); estrada para o Retiro de Pedras, 23-II-1997, fl., Romero et al. 3968 (HUFU); estrada para Sacramento, próximo ao Curral de Pedras, 18-IV1994, fl. fr., Romero et al. 924 (HRCB, HUFU, VIC); estrada São Roque-Sacramento, próximo ao Córrego dos Passageiros, 13-V-1995, fl. fr., Romero et al. 2223 (HRCB, HUFU, VIC); guarita de Sacramento, 15-IV-1997, fl., Nakajima et al. 2283 (HUFU); Sede Administrativa, 17-III-1995, fr., Romero et al. 1953 (HRCB, HUFU, VIC).

Ocorre no Equador, Honduras, Costa Rica, Colômbia, Paraguai, Argentina e Brasil (Maréchal et al. 1978), onde é citada para áreas de campos rupestres ao sul da Cadeia do Espinhaço (Dutra 2005). No PNSC, a espécie foi coletada em áreas de campo limpo com afloramentos rochosos e em campo sujo.

23. Zornia J. F. Gmel., Syst. Nat. 2(2): 1076 - 1096. 1791 [1792].

1. Folhas 2-folioladas

2. Estípulas 5-7 nervadas; folíolos glabrescentes, com glândulas puntiformes; lomentos 5-7 articulados, cerdosos 23.2. Z. glabra

2. Estípulas 9-13 nervadas; folíolos seríceos, sem glândulas punti-formes; lomentos 3-4 articulados, vilosos 23.3. Z. sericea

1. Folhas 4-folioladas ....... 23.1. Z. flemmingioides

23.1. Zornia flemmingioides Moric., P1. Nouv. Amer. 127-129. 1844.

Figura $4 \mathrm{j}$

Ervas eretas, ca. $80 \mathrm{~cm}$ alt. Estípulas lanceoladas, prolongadas abaixo do ponto de inserção, 4-15 mm compr., 5-nervadas, persistentes; estipelas ausentes. Folhas paripinadas, 4-folioladas; pecíolo 4-9 $\mathrm{mm}$ compr, glabro; raque ausente; folíolos 16-53×3-12 mm, oblongos, base obtusa, ápice agudo, esparsamente estrigosos a glabrescentes, com glândulas puntiformes. Inflorescências espiciformes, 3-7 cm compr., axilares, 6-13-flora, botão floral reto; cálice 5-laciniado, bilabiado, 4-5 mm compr., puberulento, glândulas puntiformes; corola zigomorfa, amarela com guias de néctar vináceos, vexilo ca. $6 \times 6 \mathrm{~mm}$, glabro, alas ca. $6 \times 3 \mathrm{~mm}$, pétalas da carena ca. $6 \times 2 \mathrm{~mm}$; androceu monadelfo, 10 estames, ca. $5 \mathrm{~mm}$ compr., anteras dimórficas: 5 longas e basifixas alternadas com 5 menores e dorsifixas; ovário subséssil, ca. $3 \mathrm{~mm}$ compr., barbado. Lomentos 5,5-12×1,5 mm, 2-3articulados, estrigosos, reticulados, glandulares; sementes ovais, castanho-escuras a negras.

Material examinado: BRASIL. MinAs GERAIS: PNSC, São Roque de Minas, estrada para Sacramento, 25 km da guarita de Sacramento, 22-III-1995, fl., Nakajima et al. 948 (HRCB, HUFU, VIC).

Ocorre ao longo da Cadeia do Espinhaço (Mohlenbrock 1961, Harley \& Simmons 1986, Brandão et al. 1995). No PNSC, foi coletada apenas em uma área de campo limpo com solo hidromórfico.

23.2. Zornia glabra Desv., Mem. Soc. Linn. Paris 4: 325.1826.

Figura 4k-o

Ervas eretas, ca. $20 \mathrm{~cm}$ alt. Estípulas lanceoladas, prolongadas abaixo do ponto de inserção, 13-20 mm compr., 5-7-nervadas, persistentes; estipelas ausentes. Folhas 2-folioladas; pecíolo 1-1,5 cm compr., puberulento a glabrescente; raque ausente; folíolos 12-25×2-7 mm, elípticos, oblongos, lineares, base aguda a assimétrica, ápice obtuso a agudo, glabrescentes, com glândulas puntiformes. Inflorescências espiciformes, 2-8,3 cm compr., axilares, 3-12-flora, botão floral reto; cálice 5-laciniado, bilabiado, ca. $4 \mathrm{~mm}$ compr., glabrescente; corola zigomorfa, amarela com guias de néctar vináceos, vexilo ca. $7 \times 6 \mathrm{~mm}$, glabro, alas ca. $6 \times 2 \mathrm{~mm}$, pétalas da carena ca. $7 \times 2 \mathrm{~mm}$; androceu monadelfo, 10 estames, ca. $5 \mathrm{~mm}$ compr., anteras dimórficas: 5 longas e basifixas alternadas com 5 menores e dorsifixas; ovário subséssil, ca. $5 \mathrm{~mm}$ compr., barbado. Lomentos 8-10×2-2,5 mm, 5-7articulados, cerdosos, reticulados, eglandulares; sementes ovais, castanho-escuras a negras. 


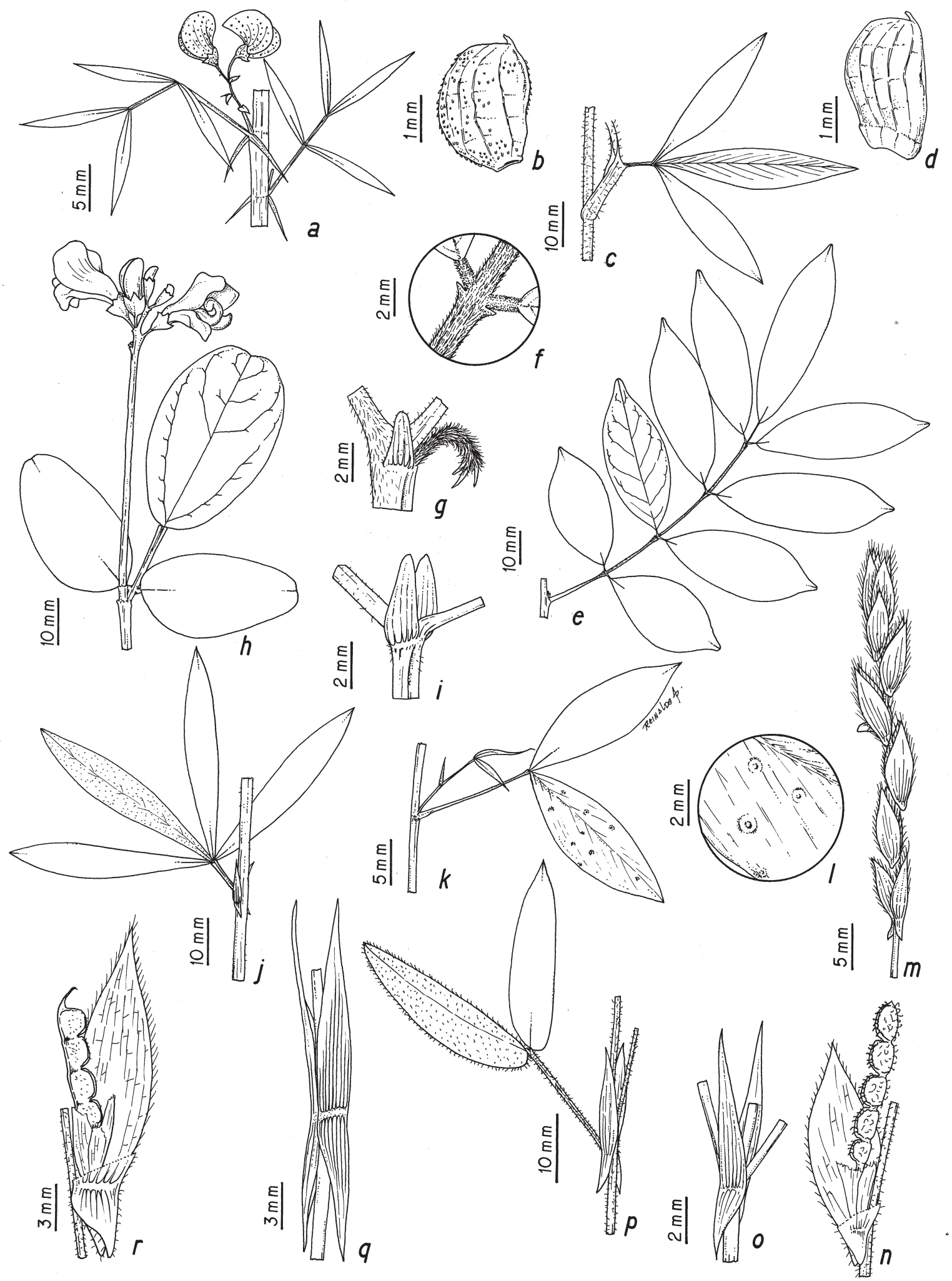

Figura 4. Poiretia angustifolia. a. Ramo (Romero et al. 1787). Stylosanthes gracilis. b. Lomento (Romero et al. 927). c-d. Stylosanthes guianensis. c. Folha e estípulas. d. Lomento (Romero et al. 2300). e-f. Swartzia apetala var. apetala. e. Folha. f. Detalhe da raque marginada (Nakajima et al. 590). Vigna candida. g. Estípula (Romero et al. 2469). Vigna firmula. h. Ramo (Romero et al. 4260). Vigna peduncularis. i. Estípulas (Romero et al. 2223). Zornia flemmingioides. j. Folha (Nakajima et al. 948). k-o. Zornia glabra. k. Folha. 1. Detalhe das glândulas puntiformes da folha. m. Inflorescência. n. Lomento. o. Detalhe das estípulas (Romero et al. 1713). p-r. Zornia sericea. p. Folha e estípulas. q. Detalhe das estípulas. r. Lomento (Romero et al. 3970). 
Materiais examinados: BRASIL. MinAs Gerais: São Roque de Minas, PNSC, estrada para Sacramento, 19-IV-1994, fl. fr., Nakajima et al. 294 (HRCB, HUFU, VIC); 11-I-1995, fl. fr., Romero et al. 1713 (HRCB, HUFU, VIC).

Ocorre da Guiana até o Brasil, onde é citada para a Bahia, Minas Gerais, Rio de Janeiro, Rio Grande do Sul (Mohlenbrock 1961) e São Paulo (Sciamarelli \& Tozzi 1996). No PNSC, apresenta ocorrência restrita às áreas de campo limpo.

23.3. Zornia sericea Moric., Pl. Nouv. Amer. 126127.1844.

Figura 4p-r

Ervas eretas, ca. 0,3 m alt. Estípulas lanceoladas, prolongadas abaixo do ponto de inserção, 14-33 mm compr., 9-13-nervadas, persistentes; estipelas ausentes. Folhas 2-folioladas; pecíolo 0,8-2,7 cm compr., seríceo; raque ausente; folíolos 9-15×1-11 mm, suborbiculares, elípticos, oblongos, lanceolados, base assimétrica, ápice obtuso a agudo, seríceos. Inflorescências espiciformes, 3,5-10,4 cm compr., axilares, 7-17-flora, botão floral reto; cálice 5-laciniado, bilabiado, ca. 4 mm compr., esparsamente estrigoso; corola zigomorfa, amarela com guias de néctar vináceos, vexilo ca. $9 \times 9 \mathrm{~mm}$, glabro, alas ca. $8 \times 4 \mathrm{~mm}$, pétalas da carena ca. $8 \times 3 \mathrm{~mm}$; androceu monadelfo, 10 estames, ca. $5 \mathrm{~mm}$ compr. anteras dimórficas: 5 longas e basifixas alternadas com 5 menores e dorsifixas; ovário subséssil, ca. $5 \mathrm{~mm}$ compr., barbado. Lomentos 15-20×1-1,5 mm, 3-4articulados, vilosos, reticulados, eglandulares; sementes ovais, castanho-escuras a negras.

Materiais examinados: BRASIL. MinAs GeraIs: São Roque de Minas, PNSC, cachoeira da Casca D'Anta, 11-I-1995, fl., Romero et al. 1734 (HRCB, HUFU, VIC); estrada para o Retiro das Pedras, próximo à divisa do Parque, 23-II-1997, fl., Romero et al. 3970 (HUFU, VIC); estrada para Sacramento, após o Curral de Pedras, 8-XII-1994, fl. fr., Romero et al. 1503 (HRCB, HUFU, VIC); estrada SacramentoSão Roque de Minas, próximo à Torre de Observação, 11-I-1998, fl., Romero et al. 5015 (HUFU, VIC).

Ocorre em formações campestres da Venezuela e do Brasil, onde é citada para o Maranhão, Bahia e Minas Gerais (Mohlenbrock 1961). No PNSC, a espécie ocorre em áreas de campo cerrado e de campo limpo.
Dentre os 41 táxons de Papilionoideae presentes no PNSC, 14,6\% apresentam ampla distribuição nas Américas, 41,4\% ocorrem apenas na América do Sul, enquanto que $44 \%$ são exclusivos da flora brasileira. Com relação à ocorrência destes táxons no Brasil, $36,5 \%$ são amplamente distribuídos, sendo citados para diferentes biomas do país, 48,7\% têm distribuição mais restrita, geralmente associada a do bioma cerrado, enquanto que $14,8 \%$ devem ser considerados táxons de rara ocorrência, não só pela pequena amplitude geográfica que apresentam, mas também pela estreita relação com fitofisionomias campestres. Deve-se ressaltar, que $48,7 \%$ dos táxons estudados são citados para campos rupestres da Cadeia do Espinhaço: 11 apresentam ampla distribuição geográfica, sete tem distribuição mais restrita no Brasil e apenas dois são considerados endêmicos do Espinhaço (L. coriaceus e Z. flemmingioides).

\section{Agradecimentos}

As autoras agradecem a Dra. Rosana Romero e ao Dr. Jimi Naoki Nakajima, do Departamento de Biociências da Universidade Federal de Uberlândia, pela coleta e doação do material para a realização do presente trabalho. Ao Dr. Luciano P. de Queiroz, pela confirmação da identificação das espécies de Collaea e Vigna. Ao Reinaldo A. Pinto, pelas ilustrações.

\section{Literatura citada}

Azevedo,A.M.G. 1981. O gênero Desmodium Desv. no Brasil - considerações taxonômicas. Dissertação de Mestrado, Universidade Estadual de Campinas, Campinas.

Barbosa-Fevereiro, V.P. 1977. Centrosema (A.P. de Candolle) Bentham do Brasil - Leguminosae-Faboideae. Rodriguésia 42: 159-219.

Barroso, G.M., Morim, M.P., Peixoto, A.L. \& Ichaso, C.L.F. 1999. Frutos e sementes: morfologia aplicada à sistemática de dicotiledôneas. Imprensa Universitária, Viçosa.

Bentham, G. 1859. Papilionaceae. In: C.F.P. Martius, S. Endlicher \& I. Urban (eds.). Flora Brasiliensis. Typographia Regia, Monachii, v. 15, pt. 1, pp. 1-216.

Bentham, G. 1862. Papilionaceae. In: C.F.P. Martius, S. Endlicher \& I. Urban (eds.). Flora Brasiliensis. Typographia Regia, Monachii, v. 15, pt. 2, pp. 217-350.

Bortoluzzi, R.L.C., Carvalho-Okano, R.M., Garcia, F.C.P. \& Tozzi, A.M.G.A. 2004. Leguminosae, Papilionoideae no Parque Estadual do Rio Doce, Minas Gerais, Brasil. II: árvores e arbustos escandentes. Acta Botanica Brasilica 18: 49-71. 
Brandão, M., Gavilanes, M.L., Araújo, M.G. \& LacaBuendia, J.P. 1995. Município de Diamantina, MG 1 Cobertura vegetal e composição florística de suas formações. Daphne 5: 28-52.

Brandão, M. \& Silva Filho, P.V. 1993. Os campos rupestres no município de Barão de Cocais, MG. Daphne 3: 11-20.

Burkart, A. 1970. Leguminosas-Faseóleas argentinas de los géneros Mucuna, Dioclea y Camptosema. Darwiniana 16: 175-218.

Burkart, A. 1971. El género Galactia (Legum. - Phaseoleae) en sudamérica con especial referencia a la Argentina y paises vecinos. Darwiniana 16: 663-796.

Carvalho, A.M. 1997. A synopsis of the genus Dalbergia (Fabaceae, Dalbergieae) in Brazil. Brittonia 49: 87-109.

Ducke, A. 1949. Notas sobre a Flora Neotrópica-II. As leguminosas da amazônia brasileira. Boletim Técnico do Instituto de Agronomia 18: 146-171.

Ducke, A. 1954. As leguminosas de Pernambuco e Paraíba. Memórias do Instituto Oswaldo Cruz 51: 417-446.

Dutra, V.F. 2005. Leguminosae Adans. nos campos rupestres do Parque Estadual do Itacolomi, Minas Gerais, Brasil: florística, preferência por habitat, aspectos reprodutivos e distribuição geográfica. Dissertação de Mestrado, Universidade Federal de Viçosa, Viçosa.

Ferreira, M.B. \& Costa, N.M.S. 1979. O gênero Stylosanthes Sw. no Brasil. EPAMIG, Belo Horizonte.

Filardi, F.L.R. 2005. Espécies lenhosas de Leguminosae na Estação Ambiental de Volta Grande, Minas Gerais, Brasil. Dissertação de Mestrado, Universidade Federal de Viçosa, Viçosa.

Flores, A.S. 2004. Taxonomia, números cromossômicos e química de espécies de Crotalaria L. (LeguminosaePapilionoideae) no Brasil. Tese de Doutorado, Universidade Estadual de Campinas, Campinas.

Funch, L.S. \& Barroso, G.M. 1999. Revisão taxonômica do gênero Periandra Mart. ex Benth. (Leguminosae, Papilionoideae, Phaseoleae). Revista Brasileira de Botânica 22: 539-564.

Garcia, F.C.P. \& Dutra, V.F. 2004. Leguminosae nos Campos Rupestres. In: CD-ROM. Simpósios, palestras e mesas redondas do $55^{\circ}$ Congresso Nacional de Botânica. Alpha Mídia Assessoria Fonográfica Ltda., Viçosa.

Gavilanes, M.L. \& Brandão, M. 1991. Flórula da Reserva Biológica Municipal do Poço Bonito, Lavras, MG. II Formação Campo Rupestre. Daphne 2: 7-18.

Gavilanes, M.L., Brandão, M., Laca-Buendia, J.P. \& Araújo, M.G. 1995. Cobertura vegetal da Serra de São José, MG, Municípios de São João Del Rei e Tiradentes. Daphne 5: 40-72.
Giulietti, A.M., Harley, R.M., Queiroz, L.P., Wanderley, M.G.L. \& Pirani, J.R. 2000. Caracterização e endemismos nos Campos Rupestres da Cadeia do Espinhaço. In: T.B. Cavalcanti \& B.M.T. Walter (eds.). Tópicos atuais em Botânica. SBB/Embrapa, Brasília, pp. 311-318.

Giulietti, A.M., Menezes, N.L., Pirani, J.R., Meguro, M. \& Wanderley, M.G.L. 1987. Flora da Serra do Cipó: caracterização e lista das espécies. Boletim de Botânica da Universidade de São Paulo 9: 1-151.

Giulietti, A.M. \& Pirani, J.R. 1988. Patterns of geographic distribution of some plant species from the Espinhaço Range, Minas Gerais and Bahia, Brazil. In: W.R. Heyer \& P.E. Vanzolini (eds.). Proceedings of a Workshop on Neotropical Distribution Patterns. Academia Brasileira de Ciências, Rio de Janeiro, pp. 39-67.

Grear, J.W. 1970. A revision of the American species of Eriosema (Leguminosae-Lotoideae). Memoirs of the New York Botanical Garden 20: 1-98.

Harley, R.M. \& Simmons, N.A. 1986. Flora of Mucugê. Chapada Diamantina - Bahia, Brazil. Royal Botanic Gardens, Kew.

IBDF - INSTITUTO BRASILEIRO DE DESENVOLVIMENTO FLORESTAL. 1981. Plano de manejo. Parque Nacional da Serra da Canastra. IBDF, Brasília.

ILDIS. 2005. International Legumes Database \& Information Service. http://www.ildis.org. (acesso em 10.12.2005).

Krukoff, B.A. \& Barneby, R.C. 1974. Conspectus of species of the genus Erythrina. Lloydia 37: 332-459.

Lewis, G.P. 1987. Legumes of Bahia. Royal Botanic Gardens, Kew.

Lewis, G.P. 1995. Leguminosae. In: B.L. Stannard (ed.). Flora of the Pico das Almas, Chapada Diamantina, Bahia, Brazil. Royal Botanic Gardens, Kew, pp. 368-394.

Lewis, G.P., Schrire, B.D., Mackinder, B.A. \& Lock, J.M. 2005. Legumes of the World. Royal Botanic Gardens, Kew.

Lorenzi, H. 2002. Árvores Brasileiras: manual de identificação e cultivo de plantas arbóreas nativas do Brasil. v. 2, 2ª ed. Editora Plantarum, São Paulo.

Mansano, V.F. \& Tozzi, A.M.G.A. 1999. Distribuição geográfica, ambiente preferencial e centros de diversidade dos membros da tribo Swartzieae na Região Sudeste do Brasil. Revista Brasileira de Botânica 22: 249-257.

Maréchal, R., Mascherpa, J.M. \& Stainer, F. 1978. Étude taxonomique d'un groupe complex d'espéces des genres Phaseolus et Vigna (Papilionaceae) sur la base de données morphologiques et polliniques, traitées par l'analyse informatique. Boissiera 28: 1-273.

Mendonça, M.P. \& Lins, L.V. 2000. Lista vermelha das espécies ameaçadas de extinção da flora de Minas Gerais. Fundação Biodiversitas, Fundação ZooBotânica de Belo Horizonte, Belo Horizonte. 
Mendonça, R.C., Felfili, J.M., Walter, B.M.T., Silva Júnior, M.C., Rezende, A.V., Filgueiras, T.S. \& Nogueira, P.E. 1998. Flora vascular do Cerrado. In: M. Sano \& S.P. Almeida (eds.). Cerrado: ambiente e flora. Planaltina: EMBRAPA-CPAC, pp. 287-556.

Miotto, S.T.S. 1988. Leguminosae-Faboideae, tribo Phaseoleae, subtribo Cajaninae. Flora Ilustrada do Rio Grande do Sul. Boletim do Instituto de Biociências 43: 1-88.

Mimura, M.R.M., Silva, T.R.S. \& Queiroz, L.P. 2004. Clitoria L. In: L.P. Queiroz (cord.). Flora de Grão-Mogol, Minas Gerais: Leguminosae. Boletim de Botânica da Universidade de São Paulo 22: 251.

Mohlenbrock, R.H. 1957. A revision of the genus Stylosanthes. Annals of the Missouri Botanical Garden 44:299-308.

Mohlenbrock, R.H. 1961. A monograph of the Leguminosae genus Zornia. Webbia 16: 1-141.

Mohlenbrock, R.H. 1963. Futher considerations in Stylosanthes (Leguminosae). Rhodora 65: 245-258.

Monteiro, R.\& Gibs, P.E. 1986. A taxonomic revision of the unifoliate species of Lupinus (Leguminosae) in Brazil. Notes from the Royal Botanic Garden Edinburgh 44: 71-104.

Mota, A.L.P. 1984. Estudo dendrológico na mata da Casca D’Anta - Parque Nacional da Serra da Canastra, MG. Dissertação de mestrado, Universidade Federal de Viçosa, Viçosa.

Müller, C. 1984. Revisão taxonômica do gênero Poiretia Vent. (Leguminosae) para o Brasil. Dissertação de Mestrado, Universidade Estadual de Campinas, Campinas.

Munhoz, C.B.R. \& Proença, C.E.B. 1998. Composição florística do Município de Alto Paraíso de Goiás na Chapada dos Veadeiros. Boletim do Herbário Ezechias Paulo Heringer 3: 102-150.

Pennington, R.T. 2003. Monograph of Andira (Leguminosae-Papilionoideae). Systematic Botany Monographs 64: 1-143.

Pirani, J.R., Giulietti, A.M., Mello-Silva, R. \& Meguro, M. 1994. Checklist and patterns of geographic distribution of the vegetation of Serra do Ambrósio, Minas Gerais, Brazil. Revista Brasileira de Botânica 17: 133-147.

Polhill, R.M. \& Raven, P.H. 1981. Advances in Legume systematics. Royal Botanical Gardens, Kew.
Queiroz, L.P. 2004. Flora de Grão-Mogol, Minas Gerais: Leguminosae. Boletim de Botânica da Universidade de São Paulo 22: 242-265

Queiroz, L.P., Mimura, M.R.M. \& Silva, T.R.S. 2004. Centrosema (DC.) Benth.. In: L.P. Queiroz (cord.). Flora de Grão-Mogol, Minas Gerais: Leguminosae. Boletim de Botânica da Universidade de São Paulo 22: 248-251.

Radford, A.E., Dickison, W.C., Massey, J.R. \& Bell, C.R. 1974. Vascular plant systematics. Harper \& Row, New York.

Romero, R. \& Nakajima, J.N. 1999. Espécies endêmicas do Parque Nacional da Serra da Canastra, Minas Gerais. Revista Brasileira de Botânica 22: 259-265.

Saint Hilaire, A. 1977. Viagem às nascentes do rio São Francisco. Tradução de R.R. Nogueira. Editora Itatiaia, Belo Horizonte.

Sakuragui, C.M., Souza, V.C. \& Queiroz, L.P. 2004. Bowdichia Kunt. In: L.P. Queiroz (coord.). Flora de Grão-Mogol, Minas Gerais: Leguminosae. Boletim de Botânica da Universidade de São Paulo 22: 247.

Sartori, A.L.B. \& Tozzi, A.M.G.A. 1998. As espécies de Machaerium Pers. (Leguminosae - Papilionoideae Dalbergieae) ocorrentes no estado de São Paulo. Revista Brasileira de Botânica 21: 211-246.

Sciamarelli, A. \& Tozzi, A.M.G.A. 1996. Zornia J.F. Gmel. (Leguminosae-Papilionoideae-Aeschnomeneae) no estado de São Paulo. Acta Botanica Brasilica 10: 237-266.

Williams, R.J. \& Clements, R.J. 1990. Taxonomy of Centrosema. In: R. Schultze-Kraft \& R.J. Clements (eds.). Centrosema, Biology, agronomy, and utilization. Centro Internacional de Agricultura Tropical, Cali, pp. 1-27.

Windler, D.R. \& Skinner, S.G. 1981. Variation in the Crotalaria breviflora complex in Brasil (Fabaceae). Phytologia 49: 425-429.

Yakovlev, G.P. 1969. A review of Sweetia and Acosmium. Notes from the Royal Botanic Garden, Edinburgh 29: 347-355.

Zappi, D.C., Lucas, E., Stannard, B.L., Lughadha, E.N., Pirani, J.R., Queiroz, L.P., Atkins, S., Hind, D.J.N., Giulietti, A.M., Harley, R.M. \& Carvalho, A.M. 2003. Lista das plantas vasculares de Catolés, Chapada Diamantina, Bahia, Brasil. Boletim de Botânica da Universidade de São Paulo 21: 345-398. 